Check for updates

Cite this: RSC Adv., 2019, 9, 14078

Received 25th February 2019

Accepted 23rd April 2019

DOI: $10.1039 / \mathrm{c} 9 \mathrm{ra01435g}$

rsc.li/rsc-advances

\section{A step-wise synthetic approach is necessary to access $\gamma$-conjugates of folate: folate-conjugated prodigiosenes $\uparrow$}

\author{
Carlotta Figliola, \$ Estelle Marchal, \$ Brandon R. Groves and Alison Thompson (iD *
}

\begin{abstract}
Despite the vast literature that describes reacting folic acid with a pharmacophore, this route is ineffective in providing the correct regioisomer of the resulting conjugate. We herein present a step-wise route to the preparation of nine folate conjugates of the tripyrrolic prodigiosene skeleton. The strict requirement for step-wise construction of the folate core is demonstrated, so as to achieve conjugation at only the desired $\gamma$-carboxylic acid and thus maintain the $\alpha$-carboxylic site for folate receptor (FR $\alpha$ ) recognition. Linkages via ethylenediamine, polyethylene glycol and glutathione are demonstrated.
\end{abstract}

\section{Introduction}

Prodigiosin is a tripyrrolic, red pigmented natural product, produced by Gram positive and Gram negative bacteria, including certain strains of Serratia marcescens (Fig. 1). ${ }^{\mathbf{1 , 2}}$ Prodigiosin is well known to exhibit immunosuppressive, antimicrobial and anticancer properties, yet modern uses extend from sunscreen $^{3}$ to antibacterial dyes for silk $^{4}$ and cotton. ${ }^{5}$ Known mechanisms of bioactivity include $\mathrm{H}^{+} / \mathrm{Cl}^{-}$exchange, oxidative DNA cleavage through $\mathrm{Cu}$ (II) chelation and signal-transduction interference. ${ }^{6-15}$ Synthetic mimics of prodigiosin, named prodigiosenes, ${ }^{16}$ with modifications on the A-, B- or C-ring ${ }^{17-24}$ have been shown to maintain the biological activity of the parent compound yet with 100-fold improvements in selectivity towards malignant cells and with 100 -fold reduction of systemic toxicity in mice compared to the natural product $\left(\mathrm{R}=\mathrm{CO}_{2} i \mathrm{Pr}, \mathrm{R}^{1}\right.$ $=$ Me, Fig. 1). ${ }^{25}$ Furthermore, the study of these synthetic analogues has enriched the knowledge of structure-activity relationships (SAR) for a better understanding of the biological activity of prodigiosin.

Folic acid (vitamin B9, Fig. 2) is considered ${ }^{26}$ a promising biomarker for triple-negative breast cancer (TNBC). ${ }^{27}$ More than $50 \%$ of TNBCs overexpress folate receptor alpha (FR $\alpha)$, as do a limited number of other cancers ${ }^{28}$ (e.g. ovarian cancers) ${ }^{29,30}$ along with those tissues where TNBC is likely to result in metastasis, such as brain and lung. ${ }^{31}$ Importantly, FR $\alpha$ is present on only a few types of healthy cells (activated macrophages and proximal tubules of kidneys), ${ }^{32}$ and, crucially, the uptake of the vitamin folic acid (as a folate salt) is not mediated

Department of Chemistry, Dalhousie University, PO Box 15000, Halifax, NS, B3H 4R2, Canada. E-mail: Alison.Thompson@dal.ca; Tel: +1-902-494-3305

$\dagger$ Electronic supplementary information (ESI) available. See DOI: 10.1039/c9ra01435g

\$ Equal contributions. by $\mathrm{FR} \alpha .^{33-35}$ Consequently, cognisant that folate-conjugated drugs do not generally enter normal cells, ${ }^{36}$ folic acid has been employed in the synthesis of multiple drug-delivery systems for chemotherapeutic treatment and imaging.

Given the potency of prodigiosenes and the targeting ability of folate, we herein report the synthesis of the first series of folate-prodigiosene conjugates. In doing so, we emphasize the ineffectiveness of the much-utilised direct synthetic approach to couple unmodified folic acid with the desired pharmacophore. Our observations and comments contrast with the vast literature that apparently describes the folate-targeted bioactivity of unpurified and uncharacterised material that results from such direct coupling. We categorically demonstrate that this direct approach, despite its wide use by others, gives rise to mixtures that include both regioisomers featuring the pharmacophore coupled to both carboxyl sites of folic acid. Instead, we demonstrate the requirement for step-wise construction of the folate core, so as to achieve conjugation at only the desired $\gamma$-carboxylic acid and thus maintenance of the $\alpha$-carboxylic site for $\mathrm{FR} \alpha$ recognition. ${ }^{37}$

\section{Results and discussion}

Our folate-prodigiosene conjugates (Fig. 3) feature prodigiosene $\mathbf{1}$ as the pharmacophore, ${ }^{38}$ with varied aliphatic spacer length $(n=2,4,8)$ leading to the folate moiety. The conjugated carbonyl group on the $\beta$-position of the C-ring has been shown to facilitate purification of prodigiosene intermediates ${ }^{\mathbf{2 1}}$ and so it, and the adjacent $\beta$-methyl substituent, were incorporated into the synthetic strategy. Linkers were chosen to increase either the lipophilicity ${ }^{39}$ (ethylenediamine, DA) or the watersolubility and biocompatibility ${ }^{\mathbf{4 0 , 4 1}}$ (polyethylene glycol, PEG) of the conjugates, or to enable intracellular redox-mediated cleavage by glutathione (disulfide, SS, Fig. 3). ${ }^{\mathbf{4 2 - 4 4}}$ 


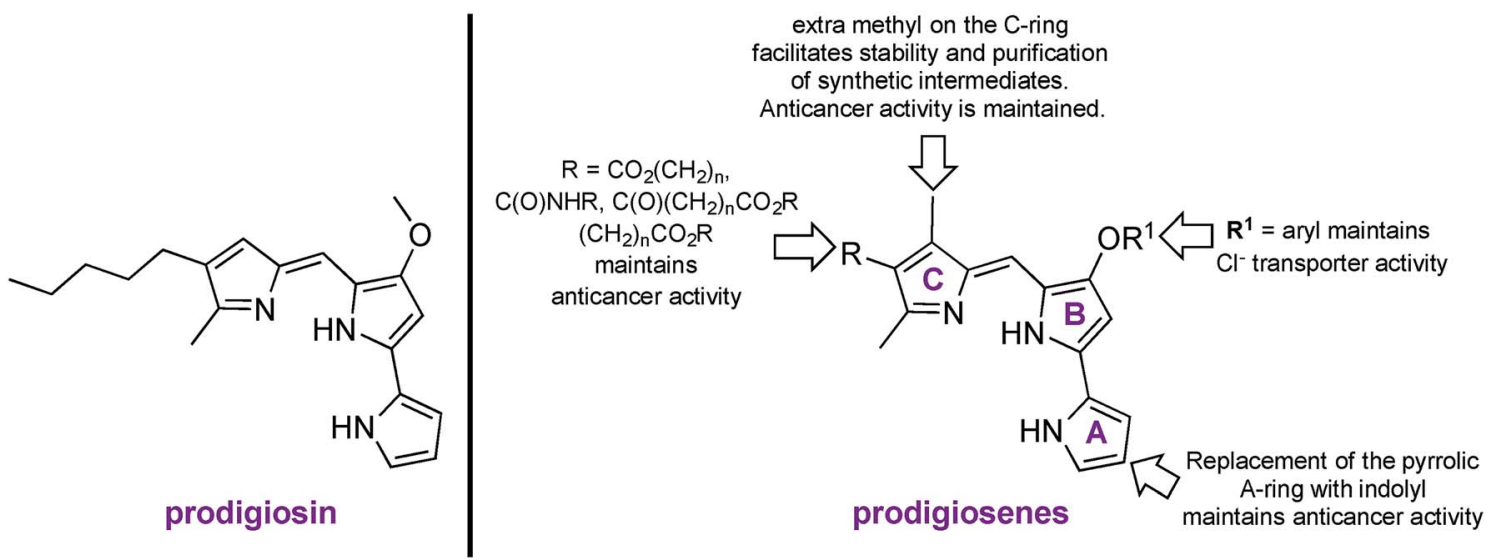

Fig. 1 Naturally occurring prodigiosin, and SAR of prodigiosene analogues. ${ }^{17-25}$

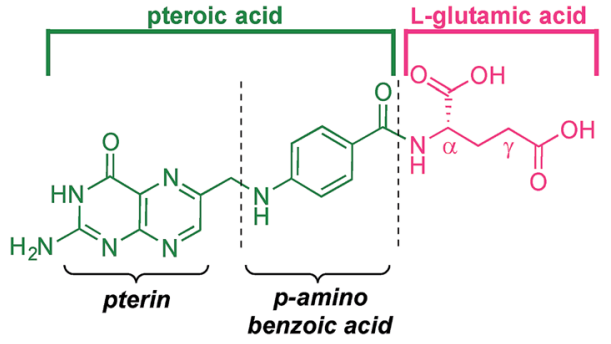

Fig. 2 Folic acid, or vitamin B9.

\section{Synthesis of linker-prodigiosene conjugates}

In order to synthesise the linker-prodigiosene conjugates 2-4ac, prodigiosenes 1a-c were coupled ${ }^{38}$ to the Boc-protected linkers 5-7 using HBTU in the presence of DMAP. ${ }^{39,40,45}$ Compounds 8-10 were thus obtained in moderate-to-excellent yields (Scheme 1, General procedure in experimental section). Deprotection, using $\mathrm{HCl}$, afforded the targeted linkerprodigiosene adducts 2-4 after basic work-up to liberate the respective free-bases. However, prodigiosene-linker conjugates $\mathbf{4 b} \cdot \mathbf{H C l}$ and $\mathbf{4 c} \cdot \mathbf{H C l}$ were used as crude salts, as the S-S bond was found to be highly sensitive to basic work-up conditions and purification using flash chromatography, both of which caused cleavage of the disulfide.

\section{$\gamma$-Coupling to folic acid and synthesis of folate-prodigiosene conjugates}

Folic acid formally consists of pteroic acid linked to L-glutamic acid through a peptide bond (Fig. 2). ${ }^{46}$ The crystal structure of human FR $\alpha$ complexed with folic acid reveals a deep binding pocket with the pteroate element of folate buried inside the receptor. ${ }^{47}$ In contrast, the glutamate moiety of folate sits at the pocket entrance. The $\alpha$-carboxylic acid of the amino-acid is involved in the interaction with the FR $\alpha$ and, thus, in the metabolism and function of folate. ${ }^{37}$ However, conjugates bound at the pendant $\gamma$-carboxylic acid, further away from the binding pocket, readily undergo binding to FR $\alpha$. As such, in order to leave the $\alpha$-position unmodified, conjugation of pharmacophores to folic acid must be specific to the $\gamma$-carboxylic acid in order to maintain ligand binding affinity. ${ }^{37}$

As shown in Fig. 4, three retrosynthetic strategies can be envisaged to achieve the desired folate-prodigiosene conjugates (top). The simplest method, Strategy A, involves the direct

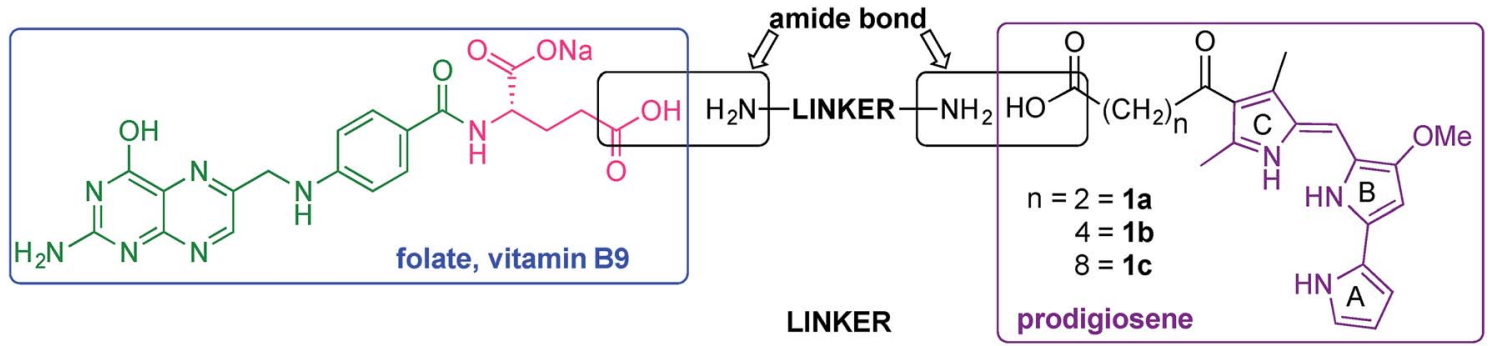

$$
\text { (DEG) }
$$

Fig. 3 Approach to targeted folate-prodigiosene conjugates. 


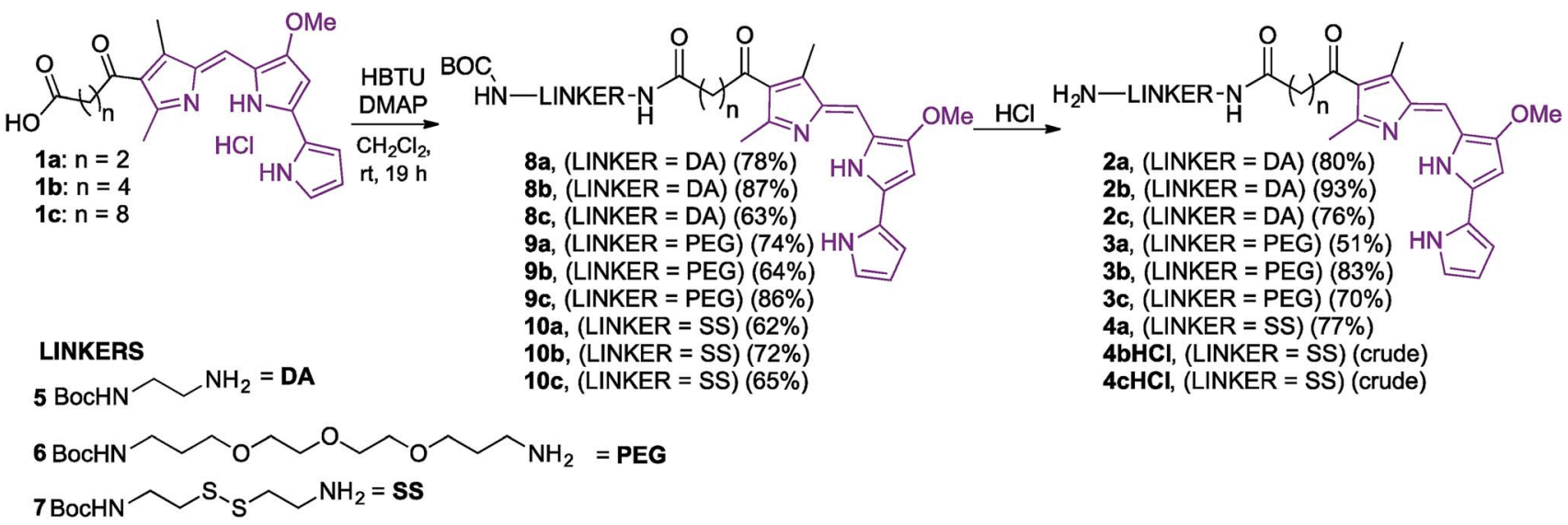

Scheme 1 Synthesis of linker-prodigiosene adducts 2-4.

coupling of folic acid with the pharmacophore. Following this approach, many literature reports appear to describe the direct activation of folic acid, followed by addition of the desired amine to afford conjugated folates. ${ }^{48-61}$ However, we met Strategy A with considerable scepticism as the presence of two carboxylic acid moieties within folic acid renders two regioisomeric coupling products clearly tangible. Given the nature of those two carboxylic acid groups, we were unable to find any rationale by which to convince ourselves that direct reaction would result in production of the required $\gamma$-conjugate. Furthermore, as conjugates to folic acid are often soluble only in DMSO the separation of the two regioisomers represents a considerable challenge. Adding to our skepticism, we found the literature regarding this direct synthetic approach to be incomplete and unreliable, due to either vagueness of purification techniques or lack of characterization such as to give assurance of purity. Indeed, upon close inspection it appears that there are many published reports that simply use the uncharacterised crude precipitate, obtained following the mixing of folic acid, coupling agent and pharmacophore, in studies relating to targeting using folate. Cognisant that coupling with DCC etc. involves ureas and other synthetic intermediates, and that these often persist in crude product mixtures, we remained unconvinced that Strategy A would be fruitful as we required a procedure that gave unequivocal access to the desired $\gamma$ conjugate of folic acid bearing prodigiosenes.

Retrosynthetic Strategies B and C (Fig. 4) involve the stepwise construction of suitably protected and activated folic acid from pteroic acid and L-glutamic acid, allowing for the selective conjugation of pharmacophore at the desired $\gamma$-carboxyl site. Strategy B requires that the $\gamma$-activated, $\alpha$-protected glutamic acid moiety be coupled with the pharmacophore prior to reaction with the pteroate portion of what will become folate. ${ }^{62-64}$ Strategy C requires that the $\gamma$-activated, $\alpha$-protected glutamic acid moiety first be coupled with activated pteroate portion to create $\gamma$-activated, $\alpha$-protected folate prior to reaction with the pharmacophore. ${ }^{65}$ Solid-state resin approaches ${ }^{66,67}$ recognise the virtues of a step-wise approach yet, compared to the lure of Strategy A, both step-wise strategies obviously demand long synthetic sequences and tedious purification processes and have not enjoyed widespread adoption. Indeed, the vast majority of published routes involving folate conjugates steer away from these step-wise approaches. ${ }^{68}$

Given the evident popularity of the direct approach offered by Strategy A, we wanted to unequivocally assess the regioselective outcome of reacting folic acid with a coupling agent and an alcohol. We thus treated folic acid with DCC and NHS, and analysed the crude product mixture. Based on the phenyl group signals in the ${ }^{1} \mathrm{H}$ NMR spectrum (see ESI $\dagger$ ), the crude NHSadduct was determined to contain $\alpha$ - and $\gamma$-adducts in an approx. $25: 75 \alpha: \gamma$ ratio. A solution of the adduct mixture in DMSO was treated with the linker-prodigiosene conjugate 2a in an attempt to form the desired amide linkage. Attempts to isolate pure material (12a) from the precipitate thus formed were completely unsuccessful (Scheme 2). Rather, the crude mixture was poorly soluble and decomposition occurred on chromatographic media (alumina and silica). Treatment of the NHS-adduct mixture with $2 \mathbf{b}$ and $2 \mathbf{c}$ also resulted in bulk precipitation, and again separation and purification of the highly insoluble material was not possible. Still intrigued by the apparent widespread success of Strategy A, we treated folic acid with DCC, NHS and a simple amine to thus employ another route by which to gain insight regarding the regioselectivity of activation. ${ }^{57}$ A solution of the $25: 75 \alpha: \gamma$ folate-NHS adduct in DMSO was treated with octyl amine, as a model amine, and the resulting precipitate analyzed using ${ }^{1} \mathrm{H}$ NMR spectroscopy. Both $\alpha$ - and $\gamma$-regioisomers were present, along with the NHSactivated folic acid, and purification proved unsuccessful given the lack of solubility of the material. In short, direct activation following Strategy A was found to be wholly unsatisfactory in the quest towards isolated and pure $\gamma$-appended conjugates of folic acid.

With firm evidence that the direct reaction of folic acid with coupling agent and alcohol/amine does not regioselectively provide the desired $\gamma$-regioisomer, we turned our attention to strategies that used sequential protection/activation. We first turned to the applicability of retrosynthetic Strategy B, involving step-wise construction of the folate moiety so as to ensure 

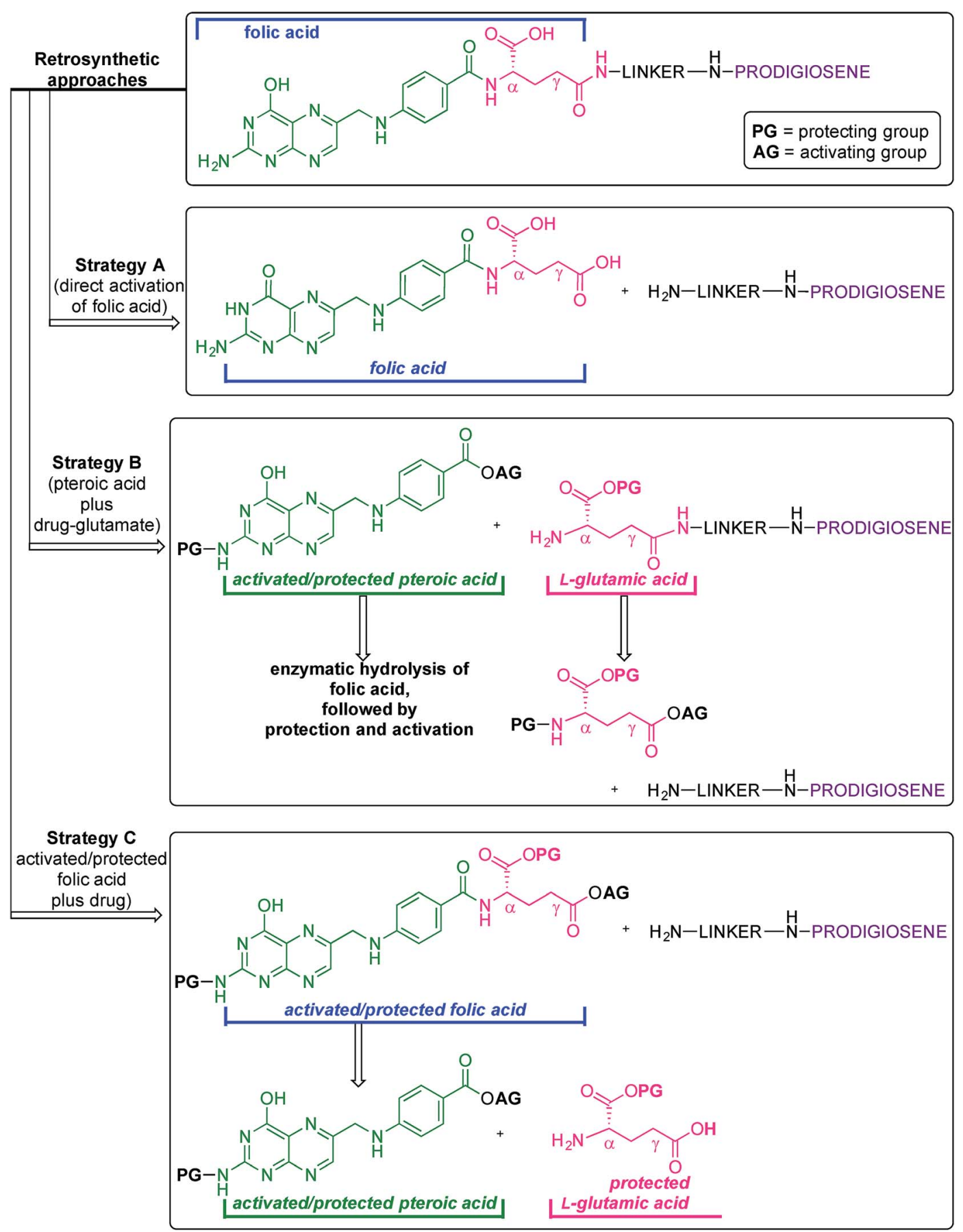

Fig. 4 Retrosynthetic approaches for the synthesis of folate-prodigiosene conjugates.

conjugation at the desired $\gamma$-carboxyl site. As shown in Fig. 4, the critical step entails coupling of suitably protected (the base portion) and activated (the acid portion) pteroic acid with a derivative of $\mathrm{L}$-glutamic acid that has been pre-linked to the prodigiosene pharmacophore by way of the $\gamma$-position. This key coupling would result in the folate-prodigiosene conjugate as a single isomer, courtesy of the previous regiospecific activation of L-glutamic acid. ${ }^{62-65,68,69}$ To embark upon Strategy B, pteroic acid was prepared following literature procedure through hydrolysis of folic acid using carboxypeptidase $G$ in the presence of $\mathrm{ZnCl}_{2}$ at $30{ }^{\circ} \mathrm{C} .{ }^{65}$ Carboxypeptidase $\mathrm{G}$ was purchased from Sigma and used as is ( $7 \mathrm{mg} ; 20$ units, since 1 unit $=1$ $\mu \mathrm{mol} \mathrm{min}^{-1}$ at optimal conditions of $30{ }^{\circ} \mathrm{C}$ and $\mathrm{pH}$ 7.3). The enzyme operates optimally at $\mathrm{pH}=7.3$. However, in our hands the reported $0.1 \mathrm{M}$ Tris- $\mathrm{HCl}$ buffer was insufficient to maintain stable $\mathrm{pH}$ after the addition of folic acid. Therefore, the initial buffer concentration was increased to $1 \mathrm{M}$ and the $\mathrm{pH}$ subsequently stabilised in the range of 7.2-7.3 via the addition of solid buffer. After 5 days, ${ }^{1} \mathrm{H}$ NMR spectroscopic analysis of the crude product mixture revealed $75 \%$ conversion of folic acid to 


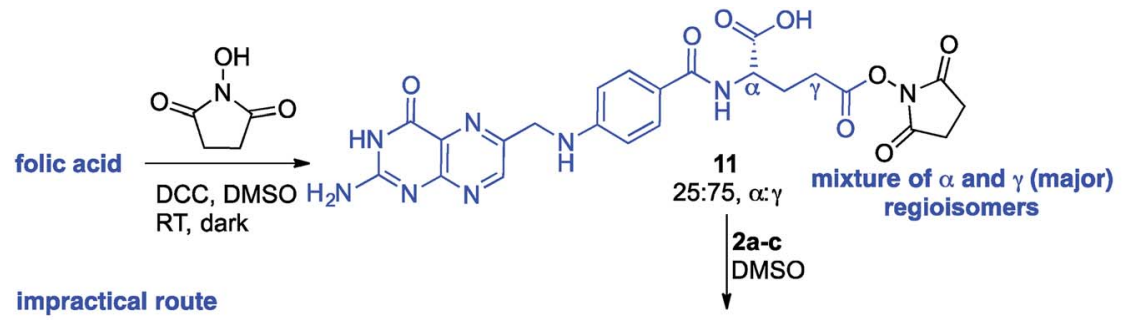

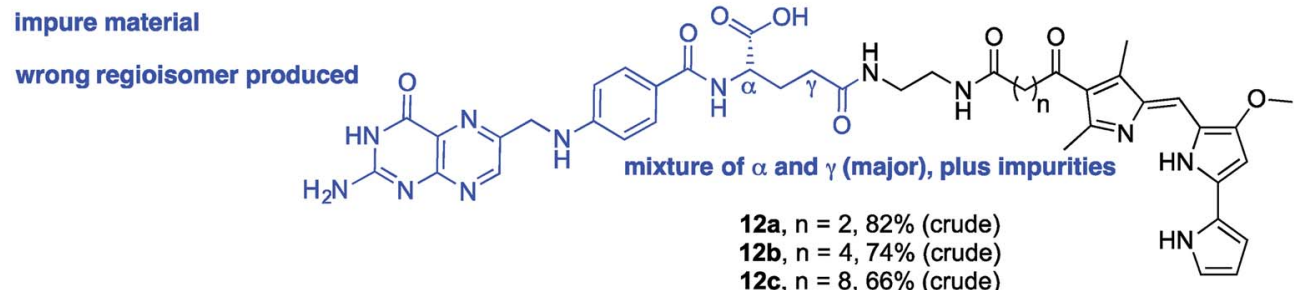

Scheme 2 Activation of folic acid with NHS and conjugation to linker-prodigiosenes $2 \mathrm{a}-\mathrm{c}$.

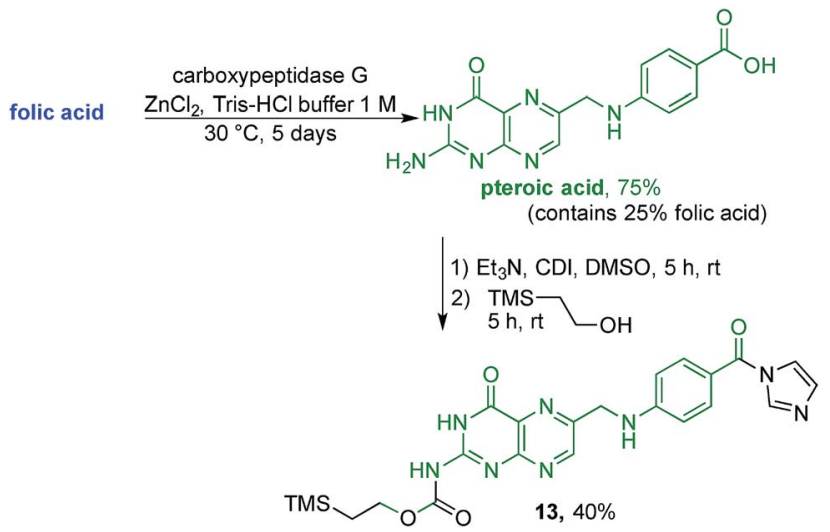

Scheme 3 Preparation of the activated Teoc-protected pteroic acid 13.

pteroic acid. The carboxylic acid of the crude pteroic acid was activated using CDI and the primary amine then protected with a trimethylsilylethoxycarbonyl (Teoc) group, to give $\mathbf{1 3}$ after purification using column chromatography on silica (Scheme 3). This purification also allowed the removal of folic acid remaining from the initial step.

The L-glutamic acid moiety of folic acid was prepared from its commercially available Boc-L-glutamic acid 5-benzyl ester derivative (14), which was first esterified at the $\alpha$-position using CDI and 2-(trimethylsilyl)ethanol, in order to obtain $\mathbf{1 5 .}$ Subsequent hydrogenolysis of the benzyl ester at the $\gamma$-position gave the protected amino acid 16, ready for coupling with prodigiosene (Scheme 4). ${ }^{65}$
Attempts to couple 16 with the dithio linker-prodigiosene conjugate $4 \mathbf{c} \cdot \mathbf{H C l}$ in the presence of HBTU and DMAP were unsuccessful and only starting material was recovered (Scheme 5). However, coupling between $\mathbf{3 b} \mathbf{b}-\mathbf{c}$ and the protected aminoacid 16 successfully afforded substrates $\mathbf{1 8 b}-\mathbf{c}$, thus crucially connecting the prodigiosene pharmacophore with the $\gamma$-position of L-glutamic acid, by way of a PEG linker. Boc-deprotection in the presence of $\mathrm{TsOH}$ in a mixture of dioxane/water gave the amines 19b-c. Strategy B (Fig. 4) then requires coupling of the drug-appended glutamic acid moiety with the activated pteroic acid, but attempts to couple $\mathbf{1 9 b}-\mathbf{c}$ to 13 resulted in only partial recovery of the substrate prodigiosenes $\mathbf{1 9 b}-\mathbf{c}$ (Scheme 5).

In turning our attention to Strategy C (Fig. 4), the L-glutamic acid derivative $\mathbf{1 6}$ was first deprotected at the amino position, and then coupled to the activated pteroic acid to successfully afford 22. This $\gamma$-carboxylic acid was then reacted with NHS to give 23 which is activated in the desired position of what will become folate (Scheme 6). ${ }^{65}$ The amines $2-4 a-c$ were reacted with a solution of 23, to provide conjugates 24-26a-c. Subsequently, the Teoc protecting group was removed with TBAF, and the resulting tetrabutylammonium salt precipitated via the addition of water. Dissolution of the salt in DMSO, followed by reaction with $\mathrm{NaOAc}$, afforded eight sodium folate-prodigiosene conjugates $\mathbf{2 7 - 2 8 a - c}$ and $\mathbf{2 9 a - b}$. However, addition of TBAF to 26c caused the cleavage of the S-S bond and the corresponding folate-prodigiosene conjugate 29c could not be isolated (Scheme 6). Clearly the step-wise approach to building folate acid, such that only the $\gamma$-carboxyl site is available for coupling, requires more synthetic effort that the direct approach. However, in contrast to Strategy A, the step-wise

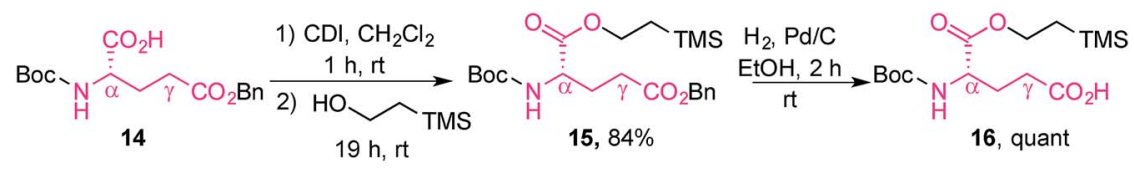

Scheme 4 Preparation of the protected glutamic acid derivative 16. 


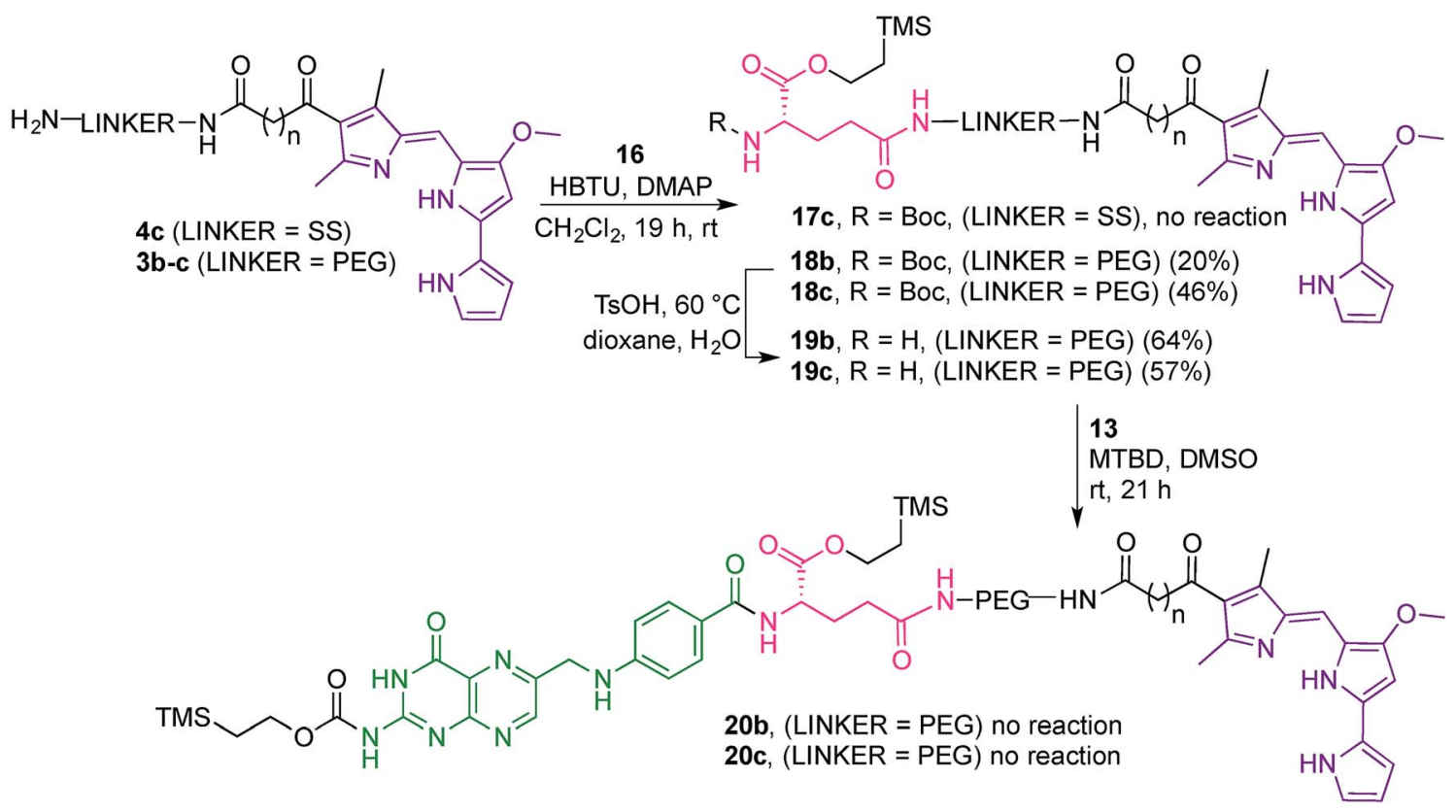

Scheme 5 Attempts to synthesise Teoc-protected folic acid-prodigiosene conjugates 20.

approaches of Strategies B and C tolerate substantiation of purity and characterization at each synthetic step and should thus be the approaches adopted for the preparation of regioisomerically pure desired conjugates of folate.

\section{Conclusions}

In summary, the first series of folate-prodigiosene conjugates have been synthesised, and full characterisation acquired. In order to increase the lipophilicity, the water-solubility and the ease of cleavage, three linkers were chosen to link the folate and the prodigiosene moieties (DA, PEG and SS respectively). Cognisant that the $\alpha$-carboxylate of folate is involved in the interaction with $\mathrm{FR} \alpha$, three synthetic approaches were investigated for the preparation of the targeted $\gamma$-adduct. The direct and most commonly used literature method involves coupling the unprotected folic acid, activated in situ, to the aminocounterpart. Despite the widespread use of this direct approach, often presented along with unsubstantiated claims as to purity and constitution of the product(s) thus obtained, we determined it to be wholly unsatisfactory as it gives mixtures of $\alpha$ - and $\gamma$-regioisomers, along with various ureas and other synthetic intermediates presenting as impurities, which are challenging to separate. We evaluated this shortcoming at the activation stage, using simply NHS, as well as through reaction with octyl amine and the prodigiosene pharmacophore. In order to access the required $\gamma$-adduct, the hydrolysis of folic acid into its two core components (pteroic acid and L-glutamic acid) was necessary. The subsequent step-wise synthesis of folic acid, with the $\alpha$-carboxylic acid protected, allowed synthesis of only the desired regioisomer thus, for the first time, connecting folic acid with the prodigiosene pharmacophore. Next steps will involve evaluation of the cytotoxicity of the conjugates, alongside optimization of drug release and internalisation.

\section{Experimental section}

All chemicals were purchased and used as received unless otherwise indicated. Moisture sensitive reactions were performed in oven-dried glassware and under a positive pressure of nitrogen. Air- and moisture-sensitive compounds were introduced via syringe or cannula through a rubber septum. Flash chromatography was performed using either Silicycle ultra-pure silica $(230-400 \mathrm{~mm})$ or 150 mesh Brockmann III activated neutral/basic alumina oxide, as indicated. The NMR spectra were recorded using a $500 \mathrm{MHz}$ spectrometer instrument using $\mathrm{CDCl}_{3}, \mathrm{MeOD}$ or DMSO as solvents and are reported in part per million (ppm). Internal solvents were referenced at $7.26 \mathrm{ppm}$ for ${ }^{1} \mathrm{H}$ and at $77.16 \mathrm{ppm}$ for ${ }^{13} \mathrm{C}$ when using $\mathrm{CDCl}_{3}$, at $3.31 \mathrm{ppm}$ for ${ }^{1} \mathrm{H}$ and at $49.00 \mathrm{ppm}$ for ${ }^{13} \mathrm{C}$ when using MeOD and at $2.50 \mathrm{ppm}$ for ${ }^{1} \mathrm{H}$ and at $39.5 \mathrm{ppm}$ for ${ }^{13} \mathrm{C}$ when using DMSO- $\mathrm{d}_{6}$. Coupling constants $(J)$ are given in Hertz $(\mathrm{Hz})$. Mass spectra were obtained using TOF and LCQ Duo ion trap instruments operating in $\mathrm{ESI}^{+/}$ - mode, as indicated. Compounds 1a-c, ${ }^{21} 5-7,{ }^{39,40,45} 11,{ }^{57}$ pteroic acid, ${ }^{65} 13,{ }^{65} 15-16,{ }^{65}$ and 21-23 (ref. 65) were prepared following literature procedures.

\section{General procedure 1 (GP1)}

Amines 5-7 (2 eq.), HBTU (1.2 eq.) and DMAP (1.2 eq.) were added to a solution of prodigiosene 1 (1 eq.) in anhydrous $\mathrm{CH}_{2} \mathrm{Cl}_{2}(0.01 \mathrm{M})$ and the reaction mixture was stirred at room temperature for $16 \mathrm{~h}$ under $\mathrm{N}_{2}$ atmosphere. The solvent was removed under reduced pressure and the crude mixture was partitioned between EtOAc and $\mathrm{NaHCO}_{3}$ (aq. sat solution). The aqueous layer was extracted with EtOAc $(\times 3)$. The combined 


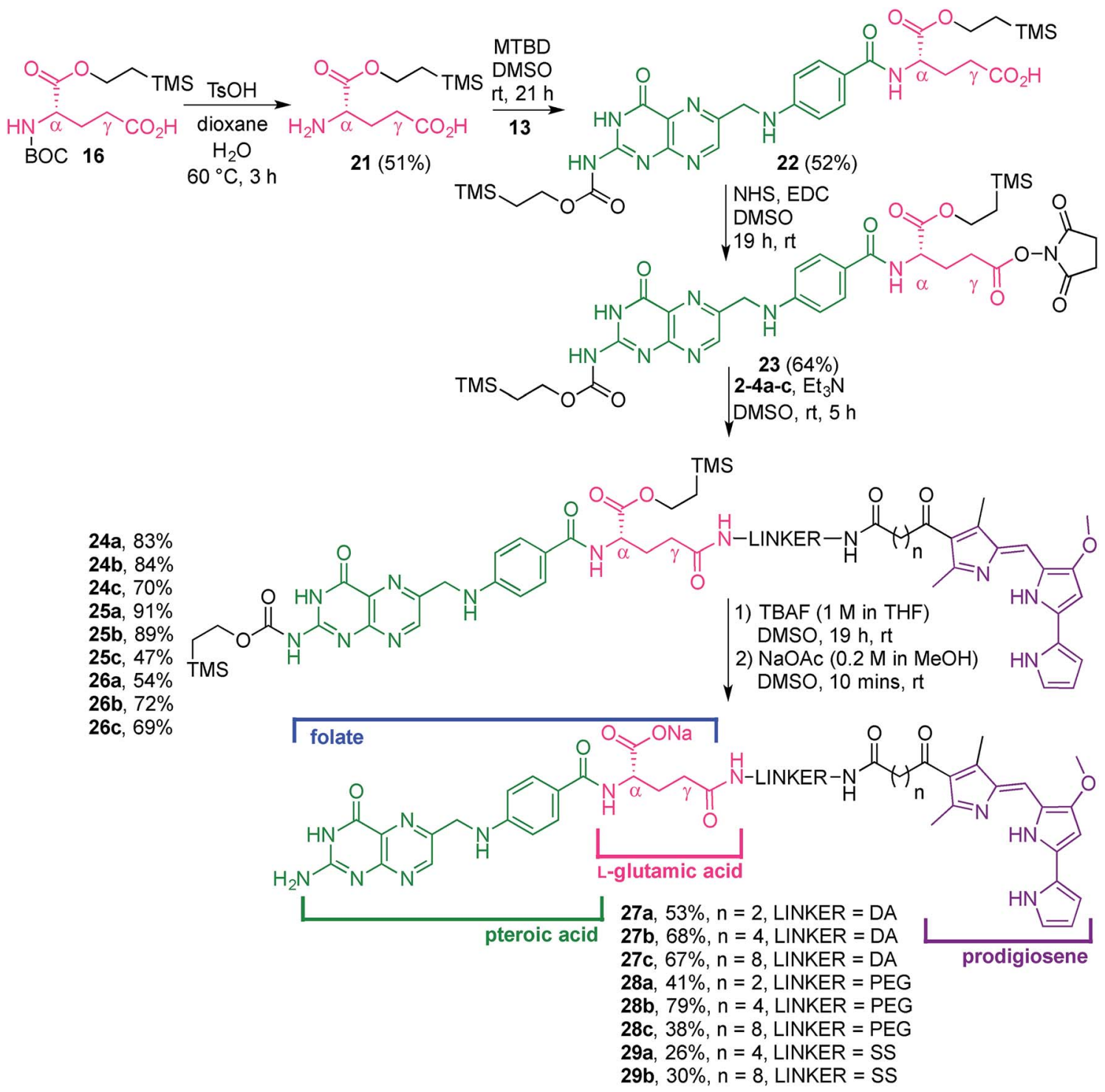

Scheme 6 Synthesis of folate-prodigiosene conjugates $27-28 a-c$ and $29 a-b$.

organic layers were washed with water $(\times 5)$, brine, dried over $\mathrm{Na}_{2} \mathrm{SO}_{4}$ and concentrated under reduced pressure.

(Z)-tert-Butyl (2-(4-(2-((4-methoxy-1H,1' H-[2,2'-bipyrrol]-5-yl) methylene)-3,5-dimethyl-2H-pyrrol-4-yl)-4-oxobutanamido)

ethyl)carbamate (8a). Compound 8a was obtained according to GP1. The crude mixture was purified by column chromatography using $\mathrm{A}_{2} \mathrm{O}_{3}$ type III basic $\left(\mathrm{CH}_{2} \mathrm{Cl}_{2}: \mathrm{MeOH} 100: 0,99: 1\right)$, followed by $\mathrm{A}_{2} \mathrm{O}_{3}$ type III neutral $\left(\mathrm{CH}_{2} \mathrm{Cl}_{2}: \mathrm{MeOH}, 100: 0\right.$, $99: 1)$ to afford $8 \mathbf{a}(0.098 \mathrm{~g}, 78 \%)$ as dark red glass. ${ }^{1} \mathrm{H}$ NMR $\left(\mathrm{CDCl}_{3}, 500 \mathrm{MHz}\right) 1.41(\mathrm{~s}, 9 \mathrm{H}), 2.21(\mathrm{~s}, 3 \mathrm{H}), 2.38(\mathrm{~s}, 3 \mathrm{H}), 2.47(\mathrm{t}, J$ $=6.1 \mathrm{~Hz}, 2 \mathrm{H}), 3.02(\mathrm{t}, J=6.3 \mathrm{~Hz}, 2 \mathrm{H}), 3.24(\mathrm{br} \mathrm{s}, 2 \mathrm{H}), 3.31(\mathrm{br} \mathrm{s}$, $2 \mathrm{H}), 3.96(\mathrm{~s}, 3 \mathrm{H}), 5.14$ (br s, 1H), $6.04(\mathrm{~s}, 1 \mathrm{H}), 6.20-6.21(\mathrm{~m}, 1 \mathrm{H})$, 6.35 (br s, 1H), 6.72 (d, J = 3.4 Hz, 1H), 6.76 (s, 1H), $6.89(\mathrm{~s}, 1 \mathrm{H})$. ${ }^{13} \mathrm{C}$ NMR $\left(\mathrm{CDCl}_{3}, 125 \mathrm{MHz}\right)$ 12.6, 14.6, 28.5, 29.8, 30.7, 38.3, 40.4 , 58.7, 79.5, 96.1, 110.8, 111.9, 113.9, 122.7, 123.3, 126.4, 128.2 , 129.8, 141.0, 142.8, 156.7, 160.9, 169.0, 173.7, 196.2.
HRMS (TOF) $(m / z):[\mathrm{M}+\mathrm{H}]^{+}$calcd for $\mathrm{C}_{27} \mathrm{H}_{36} \mathrm{~N}_{5} \mathrm{O}_{5}, 510.2711$; found, 510.2719.

(Z)-tert-Butyl (2-(6-(2-((4-methoxy-1H,1'H-[2,2'-bipyrrol]-5-yl) methylene)-3,5-dimethyl-2H-pyrrol-4-yl)-6-oxohexanamido)

ethyl)carbamate (8b). Compound $\mathbf{8 b}$ was obtained according to GP1. The crude mixture was purified by column chromatography using $\mathrm{A}_{2} \mathrm{O}_{3}$ type III basic $\left(\mathrm{CH}_{2} \mathrm{Cl}_{2}: \mathrm{MeOH} 100: 0,99: 1\right)$, precipitated with $\mathrm{CH}_{2} \mathrm{Cl}_{2}$ : hexanes (1:9), filtered and washed with hexanes to afford $\mathbf{8 b}(0.100 \mathrm{~g}, 87 \%)$ as orange glass. ${ }^{1} \mathrm{H}$ NMR ( $\left.\mathrm{CD}_{3} \mathrm{OD}, 500 \mathrm{MHz}\right) 1.42(\mathrm{~s}, 9 \mathrm{H}), 1.68-1.70(\mathrm{~m}, 4 \mathrm{H}), 2.22-$ $2.26(\mathrm{~m}, 2 \mathrm{H}), 2.39(\mathrm{~s}, 3 \mathrm{H}), 2.66(\mathrm{~s}, 3 \mathrm{H}), 2.81(\mathrm{t}, J=6.6 \mathrm{~Hz}, 2 \mathrm{H})$, $3.15(\mathrm{t}, J=6.0 \mathrm{~Hz}, 2 \mathrm{H}), 3.25(\mathrm{t}, J=6.1 \mathrm{~Hz}, 2 \mathrm{H}), 3.92(\mathrm{~s}, 3 \mathrm{H}), 6.08$ $(\mathrm{s}, 1 \mathrm{H}), 6.26-6.27(\mathrm{~m}, 1 \mathrm{H}), 6.76(\mathrm{~s}, 2 \mathrm{H}), 7.02(\mathrm{~s}, 1 \mathrm{H}) .{ }^{13} \mathrm{C} \mathrm{NMR}$ $\left(\mathrm{CD}_{3} \mathrm{OD}, 125 \mathrm{MHz}\right) 12.3,15.4,25.1,26.7,28.8,30.2,37.0,40.5$, 41.0, 43.1, 59.0, 96.7, 111.2, 111.3, 114.1, 123.6, 123.7, 128.3, 128.8, 129.8, 142.6, 144.3, 162.1, 169.6, 176.3, 200.0 (1 carbon 
atom unaccounted for). HRMS (TOF) $(\mathrm{m} / \mathrm{z})$ : $[\mathbf{M}+\mathbf{H}]^{+}$calcd for $\mathrm{C}_{29} \mathrm{H}_{40} \mathrm{~N}_{5} \mathrm{O}_{5}, 538.3024$; found, 538.3012.

(Z)-tert-Butyl (2-(10-(2-((4-methoxy-1H,1'H-[2,2'-bipyrrol]-5yl)methylene)-3,5-dimethyl-2H-pyrrol-4-yl)-10-oxodecanamido) ethyl)carbamate (8c). Compound $8 \mathrm{c}$ was obtained according to GP1. The crude mixture was purified by column chromatography using $\mathrm{Al}_{2} \mathrm{O}_{3}$ type III neutral (EtOAc 100\%) followed by $\mathrm{Al}_{2} \mathrm{O}_{3}$ type III neutral $\left(\mathrm{CH}_{2} \mathrm{Cl}_{2}: \mathrm{MeOH} 99: 1\right)$ and $\mathrm{Al}_{2} \mathrm{O}_{3}$ type III basic $\left(\mathrm{CH}_{2} \mathrm{Cl}_{2}: \mathrm{MeOH} 99.5: 0.5,99: 1,98.5: 0.5\right)$ to afford $8 \mathrm{c}$ as a red glass $(0.116 \mathrm{~g}, 63 \%) .{ }^{1} \mathrm{H} \mathrm{NMR}\left(\mathrm{CDCl}_{3}, 300 \mathrm{MHz}\right) 1.26(\mathrm{~s}$, $8 \mathrm{H}), 1.42(\mathrm{~s}, 9 \mathrm{H}), 1.58-1.60(\mathrm{~m}, 4 \mathrm{H}), 2.10-2.13(\mathrm{~m}, 5 \mathrm{H}), 2.38(\mathrm{~s}$, $3 \mathrm{H}), 2.62(\mathrm{t}, J=7.2 \mathrm{~Hz}, 2 \mathrm{H}), 3.24$ (br s, 2H), 3.31 (br s, 2H), 3.97 (s, 3H), 5.05 (br s, 1H), 6.06 (s, 1H), 6.18 (s, 1H), 6.25 (br s, 1H), 6.71-6.72 (s, 2H), 6.93 (s, 1H). ${ }^{13} \mathrm{C} \mathrm{NMR}\left(\mathrm{CDCl}_{3}, 100 \mathrm{MHz}\right) 12.4$, 14.0, 24.3, 25.8, 28.5, 29.2, 29.3, 29.4, 36.8, 40.5, 40.7, 42.8, 58.7, 79.7, 96.1, 110.7, 112.1, 113.8, 123.4, 123.6, 126.2, 128.3, 129.7, 132.3, 140.5, 142.2, 157.1, 161.1, 169.1, 174.0, 198.3. HRMS (TOF) $(\mathrm{m} / \mathrm{z}):[\mathrm{M}+\mathrm{Na}]^{+}$calcd for $\mathrm{C}_{33} \mathrm{H}_{47} \mathrm{~N}_{5} \mathrm{NaO}_{5}, 616.3436$; found, 616.3490 .

(Z)-tert-Butyl (18-(2-((4-methoxy-1H,1'H-[2,2'-bipyrrol]-5-yl) methylene)-3,5-dimethyl-2H-pyrrol-4-yl)-15,18-dioxo-4,7,10trioxa-14-azaoctadecyl)carbamate (9a). Compound 9a was obtained according to GP1. The crude mixture was purified by column chromatography using $\mathrm{Al}_{2} \mathrm{O}_{3}$ type III basic (EtOAc : hexanes $50: 50,70: 30$ EtOAc $100: 0, \mathrm{CH}_{2} \mathrm{Cl}_{2}: \mathrm{MeOH}$ $100: 0,99: 1)$ to afford 9a as an orange glass $(0.124 \mathrm{~g}, 74 \%) .{ }^{1} \mathrm{H}$ NMR $\left(\mathrm{CDCl}_{3}, 500 \mathrm{MHz}\right) 1.42(\mathrm{~s}, 9 \mathrm{H}), 1.73-1.79(\mathrm{~m}, 4 \mathrm{H}), 2.25$ (br s, 3H), $2.38(\mathrm{~s}, 3 \mathrm{H}), 2.49(\mathrm{t}, J=6.5 \mathrm{~Hz}, 2 \mathrm{H}), 3.02(\mathrm{t}, J=6.5 \mathrm{~Hz}$, $2 \mathrm{H}), 3.19-3.20(\mathrm{~m}, 2 \mathrm{H}), 3.34(\mathrm{q}, J=6.0 \mathrm{~Hz}, 2 \mathrm{H}), 3.51-3.59(\mathrm{~m}$, $8 \mathrm{H}), 3.62-3.64(\mathrm{~m}, 4 \mathrm{H}), 3.96(\mathrm{~s}, 3 \mathrm{H}), 5.02(\mathrm{br} \mathrm{s}, 1 \mathrm{H}), 6.02(\mathrm{~s}, 1 \mathrm{H})$, 6.22 (br s, 1H), 6.42 (br s, 1H), 6.72 (br s, 1H), 6.78 (br s, 1H), 6.88 (s, 1H). ${ }^{13} \mathrm{C} \mathrm{NMR}\left(\mathrm{CDCl}_{3}, 125 \mathrm{MHz}\right)$ 12.5, 14.7, 28.6, 29.1, 29.8, 30.5, 37.8, 38.2, 38.6, 58.6, 69.6, 69.9, $70.3(\times 2)$, 70.6, 79.0, 95.9, $110.8,111.9,113.8,122.8,123.4$, 126.4, 128.2, 129.9, 140.7, $142.6,156.2,160.6,168.8,172.8,196.0$ (1 carbon atom unaccounted for). HRMS (TOF) $(\mathrm{m} / \mathrm{z}):[\mathbf{M}+\mathrm{Na}]^{+}$calcd for $\mathrm{C}_{35} \mathrm{H}_{51} \mathrm{~N}_{5} \mathrm{Na}_{1} \mathrm{O}_{8}, 692.3630 ; 692.3627$.

(Z)-tert-Butyl (20-(2-((4-methoxy-1H,1'H-[2,2'-bipyrrol]-5-yl) methylene)-3,5-dimethyl-2H-pyrrol-4-yl)-15,20-dioxo-4,7,10trioxa-14-azaicosyl)carbamate (9b). Compound $9 \mathrm{~b}$ was obtained according to GP1. The crude mixture was purified by column chromatography using $\mathrm{A}_{2} \mathrm{O}_{3}$ type III neutral (hexanes : EtOAc $50: 50,40: 60,30: 70,20: 80,10: 90,0: 100$, then $\mathrm{CH}_{2} \mathrm{Cl}_{2}$ : $\mathrm{MeOH} 99: 1)$, followed by twice $\mathrm{A}_{2} \mathrm{O}_{3}$ type III basic $\left(\mathrm{CH}_{2} \mathrm{Cl}_{2}\right.$ : MeOH, $100: 0,99: 1)$ to afford $9 \mathrm{~b}(0.104 \mathrm{~g}, 64 \%)$ as dark red solid. ${ }^{1} \mathrm{H}$ NMR $\left(\mathrm{CDCl}_{3}, 500 \mathrm{MHz}\right) 1.42$ (s, 9H), 1.63-1.66 (m, 4H), 1.70-1.80 (m, 4H), 2.14-2.19 (m, 5H), 2.38 (s, 3H), 2.65-2.69 (m, $2 \mathrm{H}), 3.19(\mathrm{~d}, J=5.5 \mathrm{~Hz}, 2 \mathrm{H}), 3.34(\mathrm{dd}, J=12.0$ and $6.0 \mathrm{~Hz}, 2 \mathrm{H})$, 3.48-3.62 (m, 12H), 3.97 (s, 3H), 5.02 (m, 1H), 6.04 (s, 1H), 6.19$6.21(\mathrm{~m}, 1 \mathrm{H}), 6.39(\mathrm{br} \mathrm{s}, 1 \mathrm{H}), 6.72(\mathrm{~d}, J=3.6 \mathrm{~Hz}, 1 \mathrm{H}), 6.76(\mathrm{~s}, 1 \mathrm{H})$, 6.91 (s, 1H). ${ }^{13} \mathrm{C} \mathrm{NMR}\left(\mathrm{CDCl}_{3}, 125 \mathrm{MHz}\right) 12.3,13.9,23.7,25.4$, 28.5, 29.1, 29.7, 36.6, 37.8, 38.5, 42.3, 58.6, 70.0, $70.2(\times 2)$, 70.6, 78.9, 96.1, 110.6, 111.9, 113.9, 123.3, 123.5, 126.1, 128.1, 129.7, 140.3, 142.3, 156.2, 161.0, 169.1, 172.9, 197.5 (2 carbon atoms unaccounted for). HRMS (TOF) $(\mathrm{m} / \mathrm{z}):[\mathrm{M}+\mathrm{H}]^{+}$calcd for $\mathrm{C}_{37} \mathrm{H}_{55} \mathrm{~N}_{5} \mathrm{NaO}_{5}$, 698.4123; found, 698.4102.
(Z)-tert-Butyl (24-(2-((4-methoxy-1H,1'H-[2,2'-bipyrrol]-5-yl) methylene)-3,5-dimethyl-2H-pyrrol-4-yl)-15,24-dioxo-4,7,10trioxa-14-azatetracosyl)carbamate (9c). Compound 9c was obtained according to GP1. The crude mixture was purified by column chromatography using $\mathrm{Al}_{2} \mathrm{O}_{3}$ type III basic (EtOAc : hexanes $60: 40,80: 20$, EtOAc : MeOH $100: 0,99: 1$ ) followed by $\mathrm{Al}_{2} \mathrm{O}_{3}$ type III neutral (EtOAc: hexanes $60: 40$, $80: 20$, EtOAc : $\mathrm{MeOH} 100: 0,99: 1,98: 2)$ and $\mathrm{Al}_{2} \mathrm{O}_{3}$ type III neutral (EtOAc $100 \%)$ to afford $9 \mathrm{c}$ as a red glass $(0.200 \mathrm{~g}, 86 \%)$. ${ }^{1} \mathrm{H} \mathrm{NMR}\left(\mathrm{CDCl}_{3}, 500 \mathrm{MHz}\right) 1.28$ (br s, 8H), 1.43 (s, 9H), 1.56-1.63 $(\mathrm{m}, 4 \mathrm{H}), 1.75$ (quint., $J=6.0 \mathrm{~Hz}, 4 \mathrm{H}), 2.12(\mathrm{t}, J=7.5 \mathrm{~Hz}, 2 \mathrm{H}), 2.20$ $(\mathrm{s}, 3 \mathrm{H}), 2.39(\mathrm{~s}, 3 \mathrm{H}), 2.63(\mathrm{t}, J=7.5 \mathrm{~Hz}, 2 \mathrm{H}), 3.19-3.23(\mathrm{~m}, 2 \mathrm{H})$, $3.34(\mathrm{q}, J=6.0 \mathrm{~Hz}, 2 \mathrm{H}), 3.49-3.64(\mathrm{~m}, 12 \mathrm{H}), 3.97(\mathrm{~s}, 3 \mathrm{H}), 4.97$ (br s, 1H), 6.04 (s, 1H), 6.19-6.21 (m, 2H), $6.72(\mathrm{~d}, J=3.6 \mathrm{~Hz}$, 1H), 6.75 (br s, $1 \mathrm{H}), 6.91$ (s, $1 \mathrm{H}) .{ }^{13} \mathrm{C} \mathrm{NMR}\left(\mathrm{CDCl}_{3}, 125 \mathrm{MHz}\right)$ 12.4, 14.1, 24.3, 25.9, 28.6, 29.1, 29.3, 29.4, 29.5, 29.8, 36.9, 38.0, 38.6, 42.8, 58.6, 69.7, $70.3(\times 2)$, 70.6, 70.7, 77.4, 77.6, 79.0, 96.1, $110.7,112.1$, 113.8, 123.3, 126.2, 128.3, 129.6, 140.5, 142.1, 156.2, 160.9, 169.0, 173.2, 198.2 (1 carbon atom unaccounted for). HRMS (TOF) $(\mathrm{m} / \mathrm{z}):[\mathrm{M}+\mathrm{Na}]^{+}$calcd for $\mathrm{C}_{41} \mathrm{H}_{63} \mathrm{~N}_{5} \mathrm{Na}_{1} \mathrm{O}_{8}$, 776.4569 ; found, 776.4558.

(Z)-tert-Butyl (2-((2-(4-(2-((4-methoxy-1H,1'H-[2,2'-bipyrrol]5-yl)methylene)-3,5-dimethyl-2H-pyrrol-4-yl)-4-oxobutanamido) ethyl)disulfanyl)ethyl)carbamate (10a). Compound 10a was obtained according to GP1. The crude mixture was purified by column chromatography using $\mathrm{Al}_{2} \mathrm{O}_{3}$ type III neutral (EtOAc : hexanes $20: 80,30: 70,40: 60,50: 50,60: 40,70: 50$, $100: 0$, EtOAc: $\mathrm{MeOH} 99: 1)$ to afford 10a as a red glass (0.052 g, 72\%). ${ }^{1} \mathrm{H}$ NMR $\left(\mathrm{CDCl}_{3}, 300 \mathrm{MHz}\right) 1.43(\mathrm{~s}, 9 \mathrm{H}), 2.28$ (s, $3 \mathrm{H}), 2.38(\mathrm{~s}, 3 \mathrm{H}), 2.55(\mathrm{t}, J=6.4 \mathrm{~Hz}, 2 \mathrm{H}), 2.75-2.82(\mathrm{~m}, 4 \mathrm{H}), 3.04$ $(\mathrm{t}, J=6.4 \mathrm{~Hz}, 2 \mathrm{H}), 3.41-3.45(\mathrm{~m}, 2 \mathrm{H}), 3.55(\mathrm{q}, J=6.4 \mathrm{~Hz}, 2 \mathrm{H})$, 3.97 (s, 3H), 5.05 (br s, 1H), 6.03 (s, 1H), 6.23 (dd, $J=3.6,2.4 \mathrm{~Hz}$, $1 \mathrm{H}), 6.54(\mathrm{t}, J=5.1 \mathrm{~Hz}, 1 \mathrm{H}), 6.23(\mathrm{dd}, J=3.6,2.4 \mathrm{~Hz}, 1 \mathrm{H}), 6.52-$ $6.56(\mathrm{~m}, 1 \mathrm{H}), 6.73(\mathrm{dd}, J=3.6,1.2 \mathrm{~Hz}, 1 \mathrm{H}), 6.81$ (br s, 1H), 6.88 (s, $1 \mathrm{H}) .{ }^{13} \mathrm{C} \mathrm{NMR}\left(\mathrm{CDCl}_{3}, 125 \mathrm{MHz}\right) 12.6,14.5,28.5,30.5,38.2$, 38.4, 39.6, 58.6, 77.4, 79.7, 96.0, 110.8, 111.9, 113.9, 122.7, 123.5, 126.3, 128.1, 130.0, 140.5, 142.8, 156.0, 160.7, 168.9, 173.2, 195.9 (1 carbon atom unaccounted for). HRMS (TOF) $(\mathrm{m} / \mathrm{z})$ : $[\mathrm{M}+\mathrm{H}]^{+}$ calcd for $\mathrm{C}_{29} \mathrm{H}_{40} \mathrm{~N}_{5} \mathrm{O}_{5} \mathrm{~S}_{2}, 602.2465$; found, 602.2456 .

(Z)-tert-Butyl (2-((2-)(6-(2-)((4-methoxy-1H,1'H-[2,2'-bipyrrol]5-yl)methylene)-3,5-dimethyl-2H-pyrrol-4-yl)-6-oxohexanamido) ethyl)disulfanyl)ethyl)carbamate (10b). Compound $10 \mathrm{~b}$ was obtained according to GP1. The crude mixture was purified by column chromatography using $\mathrm{Al}_{2} \mathrm{O}_{3}$ type III neutral (EtOAc : hexanes $20: 80,30: 70,40: 60,50: 50,60: 40,70: 30$, $100: 0$ then EtOAc : MeOH 99/1) to afford 10b as a red-brown glass $(0.090 \mathrm{~g}, 75 \%) .{ }^{1} \mathrm{H} \mathrm{NMR}\left(\mathrm{CDCl}_{3}, 300 \mathrm{MHz}\right) 1.43(\mathrm{~s}, 9 \mathrm{H})$, 1.66-1.68 (m, 4H), 2.21-2.26 (m, 5H), $2.39(\mathrm{~s}, 3 \mathrm{H}), 2.69(\mathrm{t}, J=$ $6.3 \mathrm{~Hz}, 2 \mathrm{H}), 2.75(\mathrm{t}, J=6.6 \mathrm{~Hz}, 2 \mathrm{H}), 2.82(\mathrm{t}, J=6.3 \mathrm{~Hz}, 2 \mathrm{H}), 3.37-$ $3.43(\mathrm{~m}, 2 \mathrm{H}), 3.55(\mathrm{q}, J=6.1 \mathrm{~Hz}, 2 \mathrm{H}), 3.98(\mathrm{~s}, 3 \mathrm{H}), 5.02(\mathrm{br} \mathrm{s}, 1 \mathrm{H})$, 6.05 (s, 1H), 6.21 (dd, $J=3.6,2.4 \mathrm{~Hz}, 1 \mathrm{H}), 6.59$ (br s, 1H), 6.73 (dd, $J=3.6,1.2 \mathrm{~Hz}, 1 \mathrm{H}), 6.77$ (br s, $1 \mathrm{H}), 6.92$ (s, 1H). ${ }^{13} \mathrm{C}$ NMR $\left(\mathrm{CDCl}_{3}, 125 \mathrm{MHz}\right) 12.4,14.0,23.7,25.3,28.5,36.4,38.0,38.3$, 38.4, 39.6, 42.3 , 58.7, 79.7, 96.2, 110.7, 112.0, 114.0, 123.5, 126.2, $128.2,129.7,140.5,142.3,156.0,161.1,169.1,173.3,197.6$ (1 
carbon atom unaccounted for). HRMS (TOF) $(\mathrm{m} / \mathrm{z})$ : $[\mathrm{M}+\mathrm{H}]^{+}$ calcd for $\mathrm{C}_{31} \mathrm{H}_{44} \mathrm{~N}_{5} \mathrm{O}_{5} \mathrm{~S}_{2}, 630.2778$; found, 630.2770.

(Z)-tert-Butyl (2-((2-(10-(2-)((4-methoxy-1H,1'H-[2,2'-bipyrrol]5-yl)methylene)-3,5-dimethyl-2H-pyrrol-4-yl)-10oxodecanamido)ethyl)disulfanyl)ethyl)carbamate

(10c). Compound 10c was obtained according to GP1. The crude mixture was purified by column chromatography using $\mathrm{Al}_{2} \mathrm{O}_{3}$ type III basic (EtOAc: hexanes 50:50, $70: 30$ EtOAc 100\%) followed by $\mathrm{Al}_{2} \mathrm{O}_{3}$ type III neutral (EtOAc : hexanes $50: 50,60 /$ $40)$ to afford 10c as a red glass $(0.138 \mathrm{~g}, 65 \%) .{ }^{1} \mathrm{H}$ NMR $\left(\mathrm{CDCl}_{3}, 300 \mathrm{MHz}\right) 1.28(\mathrm{~s}, 8 \mathrm{H}), 1.43(\mathrm{~s}, 9 \mathrm{H}), 1.58-1.62(\mathrm{~m}, 4 \mathrm{H})$, $2.14(\mathrm{~s}, 3 \mathrm{H}), 2.18(\mathrm{t}, J=7.4 \mathrm{~Hz}, 2 \mathrm{H}), 2.39(\mathrm{~s}, 3 \mathrm{H}), 2.62(\mathrm{t}, J=$ $7.4 \mathrm{~Hz}, 2 \mathrm{H}), 2.75(\mathrm{t}, J=6.7 \mathrm{~Hz}, 2 \mathrm{H}), 2.81(\mathrm{t}, J=5.8 \mathrm{~Hz}, 2 \mathrm{H}), 3.39-$ $3.43(\mathrm{~m}, 2 \mathrm{H}), 3.54(\mathrm{q}, J=6.1 \mathrm{~Hz}, 2 \mathrm{H}), 3.98(\mathrm{~s}, 3 \mathrm{H}), 5.06(\mathrm{br} \mathrm{s}, 1 \mathrm{H})$, $6.06(\mathrm{~s}, 1 \mathrm{H}), 6.18(\mathrm{t}, J=3.0 \mathrm{~Hz}, 1 \mathrm{H}), 6.41(\mathrm{br} \mathrm{s}, 1 \mathrm{H}), 6.72(\mathrm{~d}, J=$ $3.0 \mathrm{~Hz}, 2 \mathrm{H}), 6.93(\mathrm{~s}, 1 \mathrm{H}) .{ }^{13} \mathrm{C} \mathrm{NMR}\left(\mathrm{CDCl}_{3}, 100 \mathrm{MHz}\right) 12.4,14.0$, 24.3, 25.8, 28.5, 29.3, 29.5, 36.7, 37.9, 38.2, 38.6, 39.7, 42.8, 58.7, 79.7, 96.1, 110.7, 112.1, 113.9, 123.4, 123.6, 126.2, 128.2, 129.8, 140.3, 142.2, 156.1, 161.0, 169.1, 173.7, 198.2 (2 carbon atoms unaccounted for). HRMS (TOF) $(\mathrm{m} / \mathrm{z})$ : $[\mathrm{M}+\mathrm{H}]^{+}$calcd for $\mathrm{C}_{35} \mathrm{H}_{52} \mathrm{~N}_{5} \mathrm{O}_{5} \mathrm{~S}_{2}, 686.3404$; found, 686.3386.

(Z)-N-(2-Aminoethyl)-4-(2-((4-methoxy-1H, $\mathbf{1}^{\prime} H$-[2,2'-bipyrrol]5-yl)methylene)-3,5-dimethyl-2H-pyrrol-4-yl)-4-oxobutanamide (2a). A solution of $8 \mathrm{a}(0.038 \mathrm{~g}, 0.070 \mathrm{mmol})$ in $\mathrm{MeOH}(1 \mathrm{~mL})$ was treated with $\mathrm{HCl}\left(1.2 \mathrm{~mL}, 2 \mathrm{M}\right.$ solution in $\left.\mathrm{Et}_{2} \mathrm{O}, 2.40 \mathrm{mmol}\right)$ and the reaction mixture was stirred at room temperature for $18 \mathrm{~h}$. The solvent was removed under reduced pressure and the crude mixture was dissolved in $\mathrm{MeOH}(1.5 \mathrm{~mL})$. $\mathrm{NaOH}(10 \%$ aq. solution) was added to the solution until a colour change occurred (dark red to orange). The solvent was removed under reduced pressure and the precipitate was filtered and washed with $\mathrm{H}_{2} \mathrm{O}$ to afford $2 \mathrm{a}(0.023 \mathrm{~g}, 80 \%)$ as orange solid. Mp $119^{\circ} \mathrm{C}$. ${ }^{1} \mathrm{H}$ NMR (DMSO-d 6 , $\left.500 \mathrm{MHz}\right) 2.36(\mathrm{~s}, 3 \mathrm{H}), 2.41(\mathrm{t}, J=6.7 \mathrm{~Hz}$, $2 \mathrm{H}), 2.56(\mathrm{t}, J=6.3 \mathrm{~Hz}, 2 \mathrm{H}), 2.69(\mathrm{~s}, 3 \mathrm{H}), 2.99(\mathrm{t}, J=6.8 \mathrm{~Hz}, 2 \mathrm{H})$, $3.05(\mathrm{dd}, J=12.1,6.2 \mathrm{~Hz}, 2 \mathrm{H}), 3.88(\mathrm{~s}, 3 \mathrm{H}), 6.19(\mathrm{~s}, 1 \mathrm{H}), 6.25$ (br s, $1 \mathrm{H}), 6.70(\mathrm{~s}, 1 \mathrm{H}), 6.79(\mathrm{br} \mathrm{d}, 1 \mathrm{H}, J=3.4 \mathrm{~Hz}), 7.14$ (br s, $1 \mathrm{H})$, 7.78-7.79 (m, 1H), $11.81(\mathrm{~s}, 1 \mathrm{H}) .{ }^{13} \mathrm{C}$ NMR $\left(\right.$ DMSO-d $\left._{6}, 125 \mathrm{MHz}\right)$ 11.8, 15.4, 29.4, 37.3, 41.4, 42.4, 58.5, 96.3, 110.1 (2C), 113.1, $122.1,122.9,126.3,127.5,128.2,140.8,142.1,159.4,167.3$, 171.6, 195.3 ( 1 carbon atom unaccounted for). HRMS (TOF) $(\mathrm{m} /$ z): $[\mathrm{M}+\mathrm{H}]^{+}$calcd for $\mathrm{C}_{22} \mathrm{H}_{28} \mathrm{~N}_{5} \mathrm{O}_{3}, 410.2187$; found, 410.2177.

(Z)-N-(2-Aminoethyl)-6-(2-((4-methoxy-1H, $\mathbf{1}^{\prime} H$-[2,2'-bipyrrol]5-yl)methylene)-3,5-dimethyl-2H-pyrrol-4-yl)-6-oxohexanamide

(2b). A solution of $8 \mathbf{b}(0.100 \mathrm{~g}, 0.186 \mathrm{mmol})$ in a mixture of $\mathrm{MeOH}: \mathrm{CHCl}_{3}(1: 1,4 \mathrm{~mL})$ was treated with $\mathrm{HCl}(3.3 \mathrm{~mL}, 2 \mathrm{M}$ solution in $\mathrm{Et}_{2} \mathrm{O}, 6.60 \mathrm{mmol}$ ) and the reaction mixture was stirred at room temperature for $18 \mathrm{~h}$. The solvent was removed under reduced pressure and the crude mixture was dissolved in $\mathrm{MeOH}(3.8 \mathrm{~mL})$. $\mathrm{NaOH}$ (10\% aq. solution) was added to the solution until a colour change occurred (dark red to orange). The solvent was removed under reduced pressure and the precipitate was filtered and washed with $\mathrm{H}_{2} \mathrm{O}$ to afford 2b $(0.076 \mathrm{~g}, 93 \%)$ as orange solid. ${ }^{1} \mathrm{H}$ NMR $\left(\mathrm{CD}_{3} \mathrm{OD}, 500 \mathrm{MHz}\right)$ 1.68-1.72 (m, 4H), 2.24-2.27 (m, $2 \mathrm{H}), 2.40(\mathrm{~s}, 3 \mathrm{H}), 2.66(\mathrm{~s}, 3 \mathrm{H})$, 2.79-2.83 (m, 2H), 3.28-3.32 (m, 2H), $3.92(\mathrm{~s}, 3 \mathrm{H}), 6.08(\mathrm{~s}, 1 \mathrm{H})$, 6.25-6.27 (m, 1H), 6.76-6.78 (m, 2H), 7.02-7.03 (m, 1H). ${ }^{13} \mathrm{C}$ NMR ( $\left.\mathrm{CD}_{3} \mathrm{OD}, 125 \mathrm{MHz}\right)$ 12.3, 15.4, 25.1, 26.6, 37.0, 41.5, 41.7,
43.1, 59.00, 96.7, 111.2, 111.3, 114.1, 123.5, 123.7, 128.2, 128.9, 129.8, 142.7, 144.2, 162.0, 169.6, 176.6, 199.9. HRMS (TOF) $(\mathrm{m} /$ $z):[\mathrm{M}+\mathrm{H}]^{+}$calcd for $\mathrm{C}_{24} \mathrm{H}_{32} \mathrm{~N}_{5} \mathrm{O}_{3}, 438.2500$; found, 438.2488.

(Z)- $N$-(2-Aminoethyl)-10-(2-((4-methoxy-1H,1'H-[2,2'-bipyrrol]-5-yl)methylene)-3,5-dimethyl-2 $\mathrm{H}$-pyrrol-4-yl)-10-

oxodecanamide (2c). A solution of $8 \mathbf{c}(0.073 \mathrm{~g}, 0.12 \mathrm{mmol})$ in a mixture of $\mathrm{CHCl}_{3}: \mathrm{MeOH}(1: 1,6 \mathrm{~mL})$ was treated with $\mathrm{HCl}$ $12 \mathrm{~N}(0.024 \mathrm{~mL}, 0.29 \mathrm{mmol})$ and the reaction mixture was stirred at room temperature for $7 \mathrm{~h}$. The solvent was removed under vacuum and $\mathrm{NaOH}$ (10\% aq. solution) was added drop-wise under stirring until the red solution turned orange-brown. The solvent was removed under vacuum and the precipitate was washed with water to give a dark red solid $(0.066 \mathrm{~g}, 76 \%)$. Mp $88{ }^{\circ} \mathrm{C} .{ }^{1} \mathrm{H}$ NMR (DMSO- $\left.{ }_{6}, 500 \mathrm{MHz}\right) 1.22-1.32(\mathrm{~m}, 8 \mathrm{H})$, 1.47-1.49 (m, 2H), 1.56-1.59 (m, 2H), 2.03-2.06 (m, 2H), $2.34(\mathrm{~s}$, $3 \mathrm{H}), 2.67(\mathrm{~s}, 3 \mathrm{H}), 2.72-2.74(\mathrm{~m}, 2 \mathrm{H}), 2.99-3.03(\mathrm{~m}, 2 \mathrm{H}), 3.25-3.35$ $(\mathrm{m}, 2 \mathrm{H}), 3.88(\mathrm{~s}, 3 \mathrm{H}), 6.19(\mathrm{~s}, 1 \mathrm{H}), 6.25(\mathrm{~s}, 1 \mathrm{H}), 6.70(\mathrm{~s}, 1 \mathrm{H}), 6.79$ (s, 1H), $7.14(\mathrm{~s}, 1 \mathrm{H}), 7.68(\mathrm{br} \mathrm{s}, 1 \mathrm{H}), 11.81(\mathrm{br} \mathrm{s}, 1 \mathrm{H}) .{ }^{13} \mathrm{C} \mathrm{NMR}$ (DMSO-d $\mathrm{d}_{6}, 125 \mathrm{MHz}$ ) 11.7, 15.3, 23.7, 25.3, 28.6, 28.7, 28.8, 28.9, 35.4, 41.4, 41.8, 42.2, 58.4, 96.2, 110.1 (2C), 113.0, 122.4, 122.9, 126.3, 127.4, 128.2, 140.6, 142.1, 159.3, 167.3, 172.1, 196.6. HRMS (TOF) $(m / z):[\mathrm{M}+\mathrm{H}]^{+}$calcd for $\mathrm{C}_{28} \mathrm{H}_{40} \mathrm{~N}_{5} \mathrm{O}_{3}, 494.3126$; found, 494.3129 .

(Z)-N-(3-(2-(2-(3-Aminopropoxy)ethoxy)ethoxy)propyl)-4-(2((4-methoxy-1H,1' $H$-[2,2'-bipyrrol]-5-yl)methylene)-3,5-

dimethyl-2H-pyrrol-4-yl)-4-oxobutanamide (3a). A solution of 9a $(0.125 \mathrm{~g}, 0.18 \mathrm{mmol})$ in a mixture of $\mathrm{MeOH} / \mathrm{CHCl}_{3}(1: 1,4 \mathrm{~mL})$ was treated with $\mathrm{HCl} 12 \mathrm{~N}(0.031 \mathrm{~mL}, 0.37 \mathrm{mmol})$ at room temperature. After $30 \mathrm{~min}$ additional $\mathrm{HCl} 12 \mathrm{~N}(0.030 \mathrm{~mL}, 0.36$ mmol) was added and the reaction mixture stirred for an additional 3 hours. The solvent was removed under reduced pressure and the crude mixture was dissolved in $\mathrm{MeOH}(2 \mathrm{~mL})$. $\mathrm{NaOH}(10 \%$ aq. solution) was added drop-wise under stirring until the red solution turned orange-brown. The solvent was removed under vacuum and the crude solid was purified using flash chromatography on $\mathrm{Al}_{2} \mathrm{O}_{3}$ basic type III (EtOAc 100\%, $\mathrm{CH}_{2} \mathrm{Cl}_{2}: \mathrm{MeOH} 98: 2,95: 5,90: 10$ then $\left.\mathrm{MeOH} 100 \%\right)$ to afford $3 \mathrm{a}$ as a dark red glass $(0.105 \mathrm{~g}, 51 \%) .{ }^{1} \mathrm{H}$ NMR $\left(\mathrm{CDCl}_{3}, 500\right.$ MHz) $1.68-1.73(\mathrm{~m}, 4 \mathrm{H}), 2.20(\mathrm{~s}, 3 \mathrm{H}), 2.34(\mathrm{~s}, 3 \mathrm{H}), 2.48(\mathrm{t}, J=$ $6.5 \mathrm{~Hz}, 2 \mathrm{H}), 2.84(\mathrm{t}, J=6.5 \mathrm{~Hz}, 2 \mathrm{H}), 2.97(\mathrm{t}, J=6.5 \mathrm{~Hz}, 2 \mathrm{H}), 3.28$ (q, $J=6.5 \mathrm{~Hz}, 2 \mathrm{H}), 3.47-3.60(\mathrm{~m}, 12 \mathrm{H}), 3.95(\mathrm{~s}, 3 \mathrm{H}), 6.03(\mathrm{~s}, 1 \mathrm{H})$, 6.18-6.19 (s, 1H), 6.68-6.71 (m, 2H), $6.76(\mathrm{~s}, 1 \mathrm{H}), 6.86(\mathrm{~s}, 1 \mathrm{H})$. ${ }^{13} \mathrm{C} \mathrm{NMR}\left(\mathrm{CDCl}_{3}, 125 \mathrm{MHz}\right) 12.5,14.5,29.3,30.4,30.7,37.4$, $38.0,40.1,58.6,69.3,69.9,70.0(\times 2), 70.2,70.5,96.0,110.7$, $111.7,113.9,122.7,123.5,126.4,128.1,129.8,140.6,142.7$, 160.7, 168.9, 173.2, 196.1. HRMS (TOF) $(\mathrm{m} / \mathrm{z}):[\mathrm{M}+\mathrm{H}]^{+}$calcd for $\mathrm{C}_{30} \mathrm{H}_{44} \mathrm{~N}_{5} \mathrm{O}_{6}, 570.3286$; found, 570.3295 .

$\mathrm{N}$-(3-(2-(2-(3-Aminopropoxy)ethoxy)ethoxy)propyl)-6-(2-((4methoxy-1H,1'H-[2,2'-bipyrrol]-5-yl)methylene)-3,5-dimethyl2H-pyrrol-4-yl)-6-oxohexanamide (3b). A solution of $9 b$ (0.104 g, $0.150 \mathrm{mmol})$ in a mixture of $\mathrm{MeOH}: \mathrm{CHCl}_{3}(1: 1,3.4 \mathrm{~mL})$ was treated with $\mathrm{HCl} 12 \mathrm{~N}(0.55 \mathrm{~mL}, 6.60 \mathrm{mmol})$ and the reaction mixture was stirred at room temperature for $25 \mathrm{~h}$. The solvent was removed under reduced pressure and the crude mixture was dissolved in $\mathrm{MeOH}(2 \mathrm{~mL})$. $\mathrm{NaOH}$ (6 $\mathrm{M}$ aq. solution) was added to the solution until a colour change occurred (dark red to orange). The solvent was removed under reduced pressure 
and the crude mixture was purified using flash chromatography on $\mathrm{Al}_{2} \mathrm{O}_{3}$ basic type III $\left(\mathrm{CH}_{2} \mathrm{Cl}_{2}: \mathrm{MeOH}, 9: 1\right)$ to afford $3 \mathbf{b}$ $(0.074 \mathrm{~g}, 83 \%)$ as a dark red glass. ${ }^{1} \mathrm{H} \mathrm{NMR}\left(\mathrm{CDCl}_{3}, 500 \mathrm{MHz}\right)$ 1.63 (br s, 4H), 1.66-1.71 (m, 2H), 1.72-1.77 (m, 2H), 2.15 (s, $3 \mathrm{H}), 2.17$ (br s, 2H), 2.37 (s, 3H), 2.65 (br s, 2H), 2.76 (t, 2H, J= $6.6 \mathrm{~Hz}$ ), 3.30-3.34 (m, 2H), $3.52(\mathrm{t}, 4 \mathrm{H}, J=5.8 \mathrm{~Hz}$ ), 3.56 (ddd, $12 \mathrm{H}, J=24.1,10.1,8.0 \mathrm{~Hz}), 3.96(\mathrm{~s}, 3 \mathrm{H}), 6.04(\mathrm{~s}, 1 \mathrm{H}), 6.18-6.19$ $(\mathrm{m}, 1 \mathrm{H}), 6.63(\mathrm{br} \mathrm{s}, 1 \mathrm{H}), 6.71(\mathrm{~d}, 1 \mathrm{H}, J=3.5 \mathrm{~Hz}), 6.74(\mathrm{br} \mathrm{s}, 1 \mathrm{H})$, $6.91(\mathrm{~s}, 1 \mathrm{H}) .{ }^{13} \mathrm{C} \mathrm{NMR}\left(\mathrm{CDCl}_{3}, 125 \mathrm{MHz}\right) 12.4,14.0,23.8,25.5$, 29.1, 29.8, 31.0, 33.3, 36.7, 37.7, 39.7, 42.4, 58.6, 69.6, 69.9, 70.2, 70.6, 96.2, 110.7, 112.0, 113.9, $123.4(\times 2), 126.2,128.2$, 129.7, 140.5, 142.3, 161.1, 169.1, 173.0, 197.6. HRMS (TOF) $(\mathrm{m} / \mathrm{z}):[\mathrm{M}+$ $\mathrm{H}]^{+}$calcd for $\mathrm{C}_{32} \mathrm{H}_{48} \mathrm{~N}_{5} \mathrm{O}_{6}, 598.3599$; found, 598.3577.

N-(3-(2-(2-(3-aminopropoxy)ethoxy)ethoxy)propyl)-10-(2-((4methoxy-1H,1' $H$-[2,2' -bipyrrol]-5-yl)methylene)-3,5-dimethyl2H-pyrrol-4-yl)-10-oxodecanamide (3c). A solution of $9 \mathrm{c}(0.113 \mathrm{~g}$, $0.150 \mathrm{mmol})$ in a mixture of $\mathrm{MeOH}: \mathrm{CHCl}_{3}(1: 1,3.2 \mathrm{~mL})$ was treated with $\mathrm{HCl} 12 \mathrm{~N}(0.65 \mathrm{~mL}$ of $12 \mathrm{M}$ aqueous solution, 7.80 $\mathrm{mmol}$ ) and the reaction mixture was stirred at room temperature for $5 \mathrm{~h}$. The solvent was removed under reduced pressure and the crude mixture was dissolved in $\mathrm{MeOH}(2 \mathrm{~mL}) . \mathrm{NaOH}$ (2 $\mathrm{M}$ aq. solution) was added to the solution until a colour change occurred (dark red to orange). The solvent was removed under reduced pressure and the crude mixture was purified by flash chromatography using $\mathrm{Al}_{2} \mathrm{O}_{3}$ basic type III $\left(\mathrm{CH}_{2} \mathrm{Cl}_{2}\right.$ : $\mathrm{MeOH}, 9: 1)$ to afford $3 \mathrm{c}(0.068 \mathrm{~g}, 70 \%)$ as a dark red glass. ${ }^{1} \mathrm{H}$ NMR ( $\left.\mathrm{CDCl}_{3}, 500 \mathrm{MHz}\right)$ 1.24-1.27 (m, 8H), 1.56-1.60 (m, 4H), 1.63 (br s, 4H), 1.65-1.79 (m, 4H), 2.11 (d, 2H, J=7.8 Hz), 2.15 $(\mathrm{s}, 3 \mathrm{H}), 2.38(\mathrm{~s}, 3 \mathrm{H}), 2.62(\mathrm{t}, 2 \mathrm{H}, J=7.4 \mathrm{~Hz}), 2.77(\mathrm{t}, 2 \mathrm{H}, J=6.7$ $\mathrm{Hz}), 3.33(\mathrm{dd}, 2 \mathrm{H}, J=12.2,6.0 \mathrm{~Hz}), 3.51-3.63(\mathrm{~m}, 12 \mathrm{H}), 3.97(\mathrm{~s}$, $3 \mathrm{H}), 6.05$ (s, 1H), 6.17-6.19 (m, 1H), 6.39-6.43 (br m, 1H), 6.70$6.73(\mathrm{~m}, 2 \mathrm{H}), 6.92(\mathrm{~s}, 1 \mathrm{H}) .{ }^{13} \mathrm{C} \mathrm{NMR}\left(\mathrm{CDCl}_{3}, 125 \mathrm{MHz}\right)$ 12.4, 14.1, 24.3, 25.9, 29.1, 29.3, 29.4, 29.5, 33.4, 36.9, 37.8, 39.8, 58.6, 69.6 (2C), 70.1, 70.3 (2C), 70.7, 96.1, 110.7, 112.1, 113.8, 123.3, 123.6, 126.2, 128.2, 129.7, 140.4, 142.2, 160.9, 169.1, 173.2, 198.1 (2 carbons uncounted for). HRMS (TOF) $(\mathrm{m} / \mathrm{z})$ : $[\mathrm{M}+\mathrm{H}]^{+}$calcd for $\mathrm{C}_{36} \mathrm{H}_{56} \mathrm{~N}_{5} \mathrm{O}_{6}$, 654.4225; found, 654.4203.

(Z)-N-(2-((2-Aminoethyl)disulfanyl)ethyl)-4-(2-((4-methoxy$1 H, 1^{\prime} H$-[2,2'-bipyrrol]-5-yl)methylene)-3,5-dimethyl-2H-pyrrol-4yl)-4-oxobutanamide (4a). A solution of $10 a(0.052 \mathrm{~g}, 0.077$ mmol) in a mixture of $\mathrm{MeOH}: \mathrm{CHCl}_{3}(1: 1,4 \mathrm{~mL})$ was treated with $\mathrm{HCl} 12 \mathrm{~N}(0.024,0.077 \mathrm{mmol})$. The reaction was stirred overnight at room temperature and additional $\mathrm{HCl} 12 \mathrm{~N}(0.024$, $0.077 \mathrm{mmol}$ ) was added. The solution was concentrated under reduced pressure and the crude mixture dissolved in $\mathrm{MeOH}(3$ $\mathrm{mL}$ ). $\mathrm{NaOH}$ (10\% aq. solution) was added dropwise under stirring until the red solution turned orange-brown. The solvent was removed under vacuum and the crude solid was purified using flash chromatography on $\mathrm{Al}_{2} \mathrm{O}_{3}$ basic type III (EtOAc $\left.100 \%, \mathrm{CH}_{2} \mathrm{Cl}_{2}: \mathrm{MeOH}, 95: 5\right)$ to afford $4 \mathrm{a}$ as a dark red glass $(0.033 \mathrm{~g}, 77 \%){ }^{1} \mathrm{H}$ NMR $\left(\mathrm{CDCl}_{3}, 300 \mathrm{MHz}\right) 2.25$ (s, 3H), 2.38 (s, $3 \mathrm{H}), 2.53(\mathrm{t}, J=6.3 \mathrm{~Hz}), 2.73-2.80(\mathrm{~m}, 4 \mathrm{H}), 2.97-3.05(\mathrm{~m}, 4 \mathrm{H})$, $3.56(\mathrm{q}, J=6.8 \mathrm{~Hz}, 2 \mathrm{H}), 3.97(\mathrm{~s}, 3 \mathrm{H}), 6.03(\mathrm{~s}, 1 \mathrm{H}), 6.22(\mathrm{dd}, J=$ $3.8,2.7 \mathrm{~Hz}, 1 \mathrm{H}), 6.38(\mathrm{t}, J=5.7 \mathrm{~Hz}, 1 \mathrm{H}), 6.73(\mathrm{dd}, J=3.8,1.2 \mathrm{~Hz}$, 1H), 6.79 (s, 1H), 6.89 (s, 1H). ${ }^{13} \mathrm{C} \mathrm{NMR}\left(\mathrm{CDCl}_{3}, 125 \mathrm{MHz}\right) 12.6$, 14.8, 30.6, 38.0, 38.2, 38.5, 40.8, 42.7, 58.7, 96.0, 110.9, 111.9, $113.8,122.7,123.2,126.5,128.2$, 129.8, 142.6, 160.7, 168.9,
173.1, 196.0 ( 1 carbon atom unaccounted for). HRMS (TOF) ( $\mathrm{m} /$ $z):[\mathrm{M}+\mathrm{H}]^{+}$calcd for $\mathrm{C}_{24} \mathrm{H}_{32} \mathrm{~N}_{5} \mathrm{O}_{3} \mathrm{~S}_{2}, 502.1941$; found, 502.1933. HRMS (TOF) $(m / z):[\mathrm{M}+\mathrm{H}]^{+}$calcd for $\mathrm{C}_{24} \mathrm{H}_{32} \mathrm{~N}_{5} \mathrm{O}_{3} \mathrm{~S}_{2}, 502.1933$; found, 502.1941.

$(S, Z)-2$-(Trimethylsilyl)ethyl 2-((tert-butoxycarbonyl)amino)25-(2-((4-methoxy-1H,1'H-[2,2' -bipyrrol]-5-yl)methylene)-3,5dimethyl-2H-pyrrol-4-yl)-20,25-dioxo-9,12,15-trioxa-5,19diazapentacosan-1-oate (18b). Compound $3 \mathrm{~b}$ was obtained following GP1. The crude mixture was purified using $\mathrm{Al}_{2} \mathrm{O}_{3}$ type III neutral $\left(\mathrm{CH}_{2} \mathrm{Cl}_{2} 100 \%, \mathrm{CH}_{2} \mathrm{Cl}_{2} / \mathrm{MeOH} 99 / 1,98 / 2\right)$ followed by $\mathrm{Al}_{2} \mathrm{O}_{3}$ type III basic $\left(\mathrm{CH}_{2} \mathrm{Cl}_{2} 100 \%, \mathrm{CH}_{2} \mathrm{Cl}_{2} / \mathrm{MeOH} 99 / 1\right)$ to afford $\mathbf{1 8 b}$ as a red glass $(0.020 \mathrm{~g}, 20 \%) .{ }^{1} \mathrm{H} \mathrm{NMR}\left(\mathrm{CDCl}_{3}, 300 \mathrm{MHz}\right) 0.02$ (s, 9H), 0.95-1.01 (m, 2H), 1.42 (s, 9H), 1.65-1.67 (m, 4H), 1.73$1.81(\mathrm{~m}, 4 \mathrm{H}), 1.87-1.95(\mathrm{~m}, 1 \mathrm{H}), 2.08-2.13(\mathrm{~m}, 1 \mathrm{H}), 2.16-2.20$ $(\mathrm{m}, 3 \mathrm{H}), 2.26(\mathrm{~s}, 3 \mathrm{H}), 2.39(\mathrm{~s}, 3 \mathrm{H}), 2.67-2.69(\mathrm{~m}, 2 \mathrm{H}), 3.31-3.37$ (m, 4H), 3.51-3.64 (m, 12H), $3.96(\mathrm{~s}, 3 \mathrm{H}), 4.14-4.20(\mathrm{~m}, 3 \mathrm{H}), 5.44$ $(\mathrm{d}, 1 \mathrm{H}, J=8.1 \mathrm{~Hz}), 6.02(\mathrm{~s}, 1 \mathrm{H}), 6.22(\mathrm{dd}, 1 \mathrm{H}, J=3.6,2.7 \mathrm{~Hz})$, 6.45 (br s, 1H), 6.59 (br s, 1H), $6.72(\mathrm{dd}, 1 \mathrm{H}, J=3.6,1.2 \mathrm{~Hz}), 6.79$ (br s, $1 \mathrm{H}), 6.89(\mathrm{~s}, 1 \mathrm{H}) .{ }^{13} \mathrm{C} \mathrm{NMR}\left(\mathrm{CDCl}_{3}, 125 \mathrm{MHz}\right),-1.4(3 \mathrm{C})$, 12.5, 14.7, 17.5, 23.9, 25.5, 28.5 (3C), 28.8, 29.2, 29.8, 32.8, 36.7, $37.8,37.9,42.4,53.5,58.6,63.9,70.0(\times 2), 70.2,70.6(4 \mathrm{C}), 80.0$, 96.0, 110.8, 111.9, 113.6, 123.1, 123.3, 126.6, 128.4, 129.3, 141.2, 141.9, 156.0, 160.8, 168.9, 172.1, 172.6, 173.0, 197.6. HRMS (TOF) $(\mathrm{m} / \mathrm{z}):[\mathrm{M}+\mathrm{Na}]^{+}$calcd for $\mathrm{C}_{47} \mathrm{H}_{74} \mathrm{~N}_{6} \mathrm{Na}_{1} \mathrm{O}_{11} \mathrm{Si}_{1}, 949.5077$; found, 949.5086 .

$(S, Z)$-2-(Trimethylsilyl)ethyl 2-((tert-butoxycarbonyl)amino)29-(2-((4-methoxy-1H,1'H-[2,2' -bipyrrol]-5-yl)methylene)-3,5dimethyl-2H-pyrrol-4-yl)-20,29-dioxo-9,12,15-trioxa-5,19-

diazanonacosan-1-oate (18c). Compound 3c was obtained following GP1. The crude mixture was purified using $\mathrm{Al}_{2} \mathrm{O}_{3}$ type III basic (EtOAc 100\%, EtOAc/MeOH 99/1, $\mathrm{CH}_{2} \mathrm{Cl}_{2} / \mathrm{MeOH} 98 / 2$ ), followed by $\mathrm{Al}_{2} \mathrm{O}_{3}$ type III basic $\left(\mathrm{CH}_{2} \mathrm{Cl}_{2} / \mathrm{MeOH} 99 / 1\right)$ and $\mathrm{Al}_{2} \mathrm{O}_{3}$ type III neutral $\left(\mathrm{CH}_{2} \mathrm{Cl}_{2} / \mathrm{MeOH} 99 / 1,98 / 2\right)$ to afford $18 \mathrm{c}$ as a red glass $(0.130 \mathrm{~g}, 46 \%) .{ }^{1} \mathrm{H} \mathrm{NMR}\left(\mathrm{CDCl}_{3}, 300 \mathrm{MHz}\right) 0.03(\mathrm{~s}, 9 \mathrm{H})$, 0.96-1.02 (m, 2H), $1.28(\mathrm{~s}, 8 \mathrm{H}), 1.43(\mathrm{~s}, 9 \mathrm{H}), 1.59-1.62(\mathrm{~m}, 4 \mathrm{H})$, 1.76 (quint., $4 \mathrm{H}, J=6.0 \mathrm{~Hz}), 1.87-1.97(\mathrm{~m}, 1 \mathrm{H}), 2.12(\mathrm{t}, 3 \mathrm{H}, J=$ $7.5 \mathrm{~Hz}), 2.21-2.26(\mathrm{~m}, 5 \mathrm{H}), 2.39(\mathrm{~s}, 3 \mathrm{H}), 2.64(\mathrm{t}, 2 \mathrm{H}, J=7.3 \mathrm{~Hz})$, $3.33(\mathrm{q}, 4 \mathrm{H}, J=6.0 \mathrm{~Hz}), 3.52-3.64(\mathrm{~m}, 12 \mathrm{H}), 3.96(\mathrm{~s}, 3 \mathrm{H}), 4.16-$ $4.21(\mathrm{~m}, 3 \mathrm{H}), 5.43(\mathrm{~d}, 1 \mathrm{H}, J=8.1 \mathrm{~Hz}), 6.03(\mathrm{~s}, 1 \mathrm{H}), 6.21-6.23(\mathrm{~m}$, 2H), 6.56 (br s, 1H), 6.71-6.73 (m, 1H), 6.79 (br s, 1H), 6.91 (s, 1H). ${ }^{13} \mathrm{C} \mathrm{NMR}\left(\mathrm{CDCl}_{3}, 100 \mathrm{MHz}\right),-1.4$ (3C), 12.4, 14.3, 17.5, 24.3, 25.9, 28.4 (3C), 28.8, 29.1, 29.2, 29.3, 29.4, 29.5, 32.8, 36.9, 37.7, 37.9, 42.8, 53.5, 58.6, 63.9, 69.9, 70.1, 70.5 (4C), 77.4, 77.6, 80.0, 96.0, 110.8, 112.1, 113.8, 123.3, 123.5, 126.3, 128.2, 129.7, 142.1, 155.9, 168.9, 172.1, 172.6, 173.4, 198.2. HRMS (TOF) (m/ $z):[\mathrm{M}+\mathrm{Na}]^{+}$calcd for $\mathrm{C}_{51} \mathrm{H}_{82} \mathrm{~N}_{6} \mathrm{Na}_{1} \mathrm{O}_{11} \mathrm{Si}_{1}, 1005.5703$; found, 1005.5713.

$(S, Z)$-2-(Trimethylsilyl)ethyl 2-amino-25-(2-((4-methoxy$1 \mathrm{H}, 1^{\prime} \mathrm{H}$-[2,2'-bipyrrol]-5-yl)methylene)-3,5-dimethyl-2H-pyrrol-4yl)-20,25-dioxo-9,12,15-trioxa-5,19-diazapentacosan-1-oate

(19b). Prodigiosene 18b (0.020 g, $0.021 \mathrm{mmol})$ was dissolved in a mixture of dioxane : water $(1: 1,1 \mathrm{~mL})$ and PTSA $(0.016 \mathrm{~g}$, $0.052 \mathrm{mmol}$ ) was added. The reaction was stirred at $60{ }^{\circ} \mathrm{C}$ for 3 hours and additional PTSA (0.016 g, $0.052 \mathrm{mmol})$ was added. After $16 \mathrm{~h}$ the solvent was removed under reduced pressure the crude solid was purified using $\mathrm{Al}_{2} \mathrm{O}_{3}$ type III basic $\left(\mathrm{CH}_{2} \mathrm{Cl}_{2} /\right.$ $\mathrm{MeOH}$ 99/1) to afford $19 \mathrm{~b}$ as an orange glass (0.011 g, 64\%). ${ }^{1} \mathrm{H}$ 
NMR (CDCl, $300 \mathrm{MHz}) 0.04$ (s, 9H), 0.96-1.02 (m, 2H), 1.65$1.68(\mathrm{~m}, 4 \mathrm{H}), 1.73-1.82(\mathrm{~m}, 5 \mathrm{H}), 2.04-2.13(\mathrm{~m}, 1 \mathrm{H}), 2.15-2.29$ (m, 2H), 2.32-2.40 (m, 2H), $2.68(\mathrm{~s}, 3 \mathrm{H}), 2.72(\mathrm{~s}, 3 \mathrm{H}), 3.30-3.43$ (m, 2H), 3.50-3.64 (m, 5H), $3.96(\mathrm{~s}, 3 \mathrm{H}), 4.15-4.21(\mathrm{~m}, 2 \mathrm{H}), 6.01$ $(\mathrm{s}, 1 \mathrm{H}), 6.23-6.25(\mathrm{~m}, 1 \mathrm{H}), 6.45(\mathrm{t}, 1 \mathrm{H}, J=5.1 \mathrm{~Hz}), 6.51(\mathrm{t}, 1 \mathrm{H}, J=$ $4.8 \mathrm{~Hz}), 6.72(\mathrm{~d}, 1 \mathrm{H}, J=3.6 \mathrm{~Hz}), 6.84(\mathrm{br} \mathrm{s}, 1 \mathrm{H}), 6.89(\mathrm{~s}, 1 \mathrm{H}) .{ }^{13} \mathrm{C}$ NMR ( $\left.\mathrm{CDCl}_{3}, 100 \mathrm{MHz}\right),-1.4$ (3C), 12.5, 14.9, 17.6, 23.9, 25.5, 29.2, 29.3, 30.5, 33.0, 36.7, 37.8, 42.4, 54.2, 58.6, 63.5, 70.0, 70.1, 70.2 , 70.6 (4C), 95.9, 110.8, 111.9, 113.5, 123.0, 123.2, 126.7, 128.4, 129.2, 141.4, 141.7, 160.6, 168.8, 172.5, 173.0, 175.9, 197.6.0. HRMS (TOF) $(\mathrm{m} / z):[\mathrm{M}+\mathrm{Na}]^{+}$calcd for $\mathrm{C}_{42} \mathrm{H}_{66} \mathrm{~N}_{6} \mathrm{Na}_{1}$ $\mathrm{O}_{9} \mathrm{Si}_{1}, 849.4553$; found, 849.4557.

$(S, Z)$-2-(Trimethylsilyl)ethyl 2-amino-29-(2-((4-methoxy$1 H, 1^{\prime} H$-[2,2'-bipyrrol]-5-yl)methylene)-3,5-dimethyl-2H-pyrrol-4yl)-20,29-dioxo-9,12,15-trioxa-5,19-diazanonacosan-1-oate (19c). Prodigiosene $18 \mathrm{c}(0.130 \mathrm{~g}, 0.13 \mathrm{mmol})$ was dissolved in a mixture of dioxane : water $(1: 1,6 \mathrm{~mL})$ and PTSA $(0.063 \mathrm{~g}, 0.32$ mmol) was added. The reaction was stirred at $60{ }^{\circ} \mathrm{C}$ for 3 hours and additional PTSA (0.063 $\mathrm{mg}, 0.32 \mathrm{mmol}$ ) was added. After $16 \mathrm{~h}$ the reaction mixture was quenched by addition of $\mathrm{NaHCO}_{3}$ solid until the dark red solution turned dark brown. The solvent were removed under vacuum and the crude solid was purified using $\mathrm{Al}_{2} \mathrm{O}_{3}$ type III basic $\left(\mathrm{CH}_{2} \mathrm{Cl}_{2} / \mathrm{MeOH} 98 / 2,95 / 5\right)$ to afford $19 \mathrm{c}$ as an orange glass $(0.066 \mathrm{~g}, 57 \%) .{ }^{1} \mathrm{H} \mathrm{NMR}\left(\mathrm{CDCl}_{3}, 300\right.$ MHz) 0.03 (s, 9H), 0.96-1.01 (m, 2H), 1.24-1.27 (m, 11H), 1.58$1.60(\mathrm{~m}, 4 \mathrm{H}), 1.74$ (quint., $4 \mathrm{H}, J=6.1 \mathrm{~Hz}), 2.09-2.14(\mathrm{~m}, 3 \mathrm{H})$, $2.19(\mathrm{~s}, 3 \mathrm{H}), 2.29(\mathrm{t}, 2 \mathrm{H}, J=7.3 \mathrm{~Hz}), 2.38(\mathrm{~s}, 3 \mathrm{H}), 2.63(\mathrm{t}, 2 \mathrm{H}, J=$ $7.3 \mathrm{~Hz}), 3.32$ (q, $4 \mathrm{H}, J=6.1 \mathrm{~Hz}), 3.38-3.43(\mathrm{~m}, 1 \mathrm{H}), 3.50-3.64(\mathrm{~m}$, $13 \mathrm{H}), 3.96$ (s, 3H), 4.15-4.21 (m, 2H), 6.04 (s, 1H), 6.19 (dd, 1H, $=3.6,2.7 \mathrm{~Hz}), 6.24(\mathrm{br} \mathrm{s}, 1 \mathrm{H}), 6.49(\mathrm{br} \mathrm{s}, 1 \mathrm{H}), 6.71(\mathrm{dd}, 1 \mathrm{H}, J=$ 3.6, $1.1 \mathrm{~Hz}), 6.74-6.75(\mathrm{~m}, 1 \mathrm{H}), 6.91(\mathrm{~s}, 1 \mathrm{H}) .{ }^{13} \mathrm{C} \mathrm{NMR}\left(\mathrm{CDCl}_{3}\right.$, $125 \mathrm{MHz}),-1.4$ (3C), 12.4, 14.3, 17.6, 24.3, 25.9, 29.2, 29.3, 29.4, $29.5,29.8,30.5,32.9,36.9,37.8(\times 2), 42.8,54.1,58.6,63.4,70.0$ $(\times 2), 70.2,70.6(4 \mathrm{C}), 96.0,110.7,112.1,113.7,123.2,123.5$, $126.3,128.3,129.5,140.8,142.0,160.8,179.0,172.4,173.3$, 175.9, 198.2. HRMS (TOF) $(\mathrm{m} / \mathrm{z}):[\mathrm{M}+\mathrm{Na}]^{+}$calcd for $\mathrm{C}_{46} \mathrm{H}_{74} \mathrm{~N}_{6}$ $\mathrm{Na}_{1} \mathrm{O}_{9} \mathrm{Si}_{1}, 905.5179$; found, 905.5145 .

\section{General procedure 2 (GP2)}

A solution of linker-prodigiosene conjugate (1 eq.) and 23 (1 eq.) in anhydrous DMSO (0.05 M) was treated with $\mathrm{NEt}_{3}$ (2 eq.). The resulting reaction mixture was stirred at room temperature for $5 \mathrm{~h}$ under $\mathrm{N}_{2}$ atmosphere. Water was added to the reaction mixture until a precipitate formed, which was isolated via microfiltration, then washed 3 times with water and dried under vacuum.

Teoc-FA-DA-prod(C2) (24a). Compound 24a was obtained according to GP2 as an orange solid (0.096 g, 83\%). Mp 148$150{ }^{\circ} \mathrm{C} .{ }^{1} \mathrm{H}$ NMR (DMSO-d $\left.6,500 \mathrm{MHz}\right) 0.02$ (s, 9H), 0.07 (s, 9H), 0.93-0.96 (m, 2H), 1.02-1.06 (m, 2H), 1.37 (s, 6H), 1.92-2.27 (m, $4 \mathrm{H}), 2.36(\mathrm{~s}, 3 \mathrm{H}), 2.68(\mathrm{~s}, 3 \mathrm{H}), 2.73(\mathrm{~s}, 1 \mathrm{H}), 2.98-3.00(\mathrm{~m}, 4 \mathrm{H})$, 3.88 (s, 3H), 4.10-4.16 (m, 2H), 4.25-4.30 (m, 2H), 4.35 (br s, $1 \mathrm{H}), 4.57$ (br s, 2H), 6.17 (s, 1H), 6.25 (s, 1H), 6.67 (br d, $2 \mathrm{H}, J=$ $7.0 \mathrm{~Hz}$ ), 6.79 (br s, 1H), 6.83 (br s, 1H), 7.11 (br s, 1H), 7.66 (br d, $3 \mathrm{H}, J=7.2 \mathrm{~Hz}$ ), 8.16 (br s, $1 \mathrm{H}), 8.78(\mathrm{~s}, 1 \mathrm{H}), 11.70(\mathrm{br} \mathrm{s}, 1 \mathrm{H}) .{ }^{13} \mathrm{C}$ NMR (DMSO-d $6125 \mathrm{MHz}$ ), -1.5 (6C), 11.9, 15.4, 16.8, 17.1,
26.4, 28.2, 29.5, 31.8, 37.3 (2C), 46.0, 52.3, 58.4, 62.4, 64.1, 77.6, 96.3, 110.1, 111.2 (2C), 113.1, 121.3, 122.1, 122.9, 126.4, 127.5, 128.2, 129.0 (2C), 129.8, 140.9, 142.2, 148.9, 150.7, 151.4, 154.9, $155.3,155.6,159.5,160.9,166.4$, 167.4, 171.6, 171.8, 172.3, 195.3. HRMS (TOF) $(\mathrm{m} / z):[\mathrm{M}+\mathrm{H}]^{+}$calcd for $\mathrm{C}_{52} \mathrm{H}_{69} \mathrm{~N}_{12} \mathrm{NaO}_{10} \mathrm{Si}_{2}$, 1077.4793; found, 1077.4748.

Teoc-FA-DA-prod(C4) (24b). Compound 24b was obtained according to GP2 as orange solid (0.096 g, 84\%). Mp 138-140 ${ }^{\circ} \mathrm{C}$. ${ }^{1} \mathrm{H}$ NMR (DMSO-d $\left.6,500 \mathrm{MHz}\right) 0.00$ (s, 9H), 0.05 (s, 9H), 0.860.87 (m, 3H), 0.91-0.94 (m, 2H), 1.02-1.05 (m, 3H), 1.24-1.28 (m, 1H), 1.36 (br s, 3H), 1.54 (br s, 4H), 1.91-2.07 (m, 4H), 2.18 (br s, 2H), $2.34(\mathrm{~s}, 3 \mathrm{H}), 2.67(\mathrm{~s}, 3 \mathrm{H}), 2.72(\mathrm{br} \mathrm{s}, 2 \mathrm{H}), 3.06(\mathrm{~m}, 4 \mathrm{H})$, 3.87 (s, 3H), 4.09-4.12 (m, 2H), 4.28-4.29 (m, 2H), 4.58 (br s, $3 \mathrm{H}), 6.18(\mathrm{~s}, 1 \mathrm{H}), 6.24(\mathrm{~s}, 1 \mathrm{H}), 6.65(\mathrm{br} \mathrm{d}, 2 \mathrm{H}, J=7.0 \mathrm{~Hz}), 6.68(\mathrm{~s}$, 1H), 6.78 (br s, 1H), 6.99 (br s, 1H), 7.13 (s, 1H), 7.65 (br d, 2H, $=7.0 \mathrm{~Hz}), 7.77$ (br s, $1 \mathrm{H}), 7.85$ (br s, $1 \mathrm{H}), 8.28-8.31(\mathrm{~m}, 1 \mathrm{H}), 8.81$ (s, 1H), 11.55 (br s, 2H), 11.81 (br s, 1H). ${ }^{13} \mathrm{C}$ NMR (DMSO-d 6 , $125 \mathrm{MHz}),-1.5$ (6C), 11.8, 15.4, 16.9, 17.1, 23.4, 25.0, 26.4, 28.2, 31.8, 35.5, 38.3, 38.5, 41.6, 46.0, 52.3, 58.4, 62.4, 64.6, 79.2, 96.2, $110.1,111.3,113.0,121.4,122.3,122.9,126.3,127.5,128.2$, $128.7,129.1,129.9,140.8,142.2$, 149.1, 149.2, 150.7, 151.9, 154.5 , 155.0, 159.4, 159.6, 166.4, 167.4, 171.6, 172.2, 172.3, 196.4. HRMS (TOF) $(\mathrm{m} / \mathrm{z}):[\mathrm{M}+\mathrm{H}]^{+}$calcd for $\mathrm{C}_{54} \mathrm{H}_{73} \mathrm{~N}_{12} \mathrm{O}_{10} \mathrm{Si}_{2}$, 1105.5106; found, 1105.5086 .

Teoc-FA-DA-prod(C4) (24c). Compound 24c was obtained according to GP2 as a dark red solid (0.098 g, 70\%). Mp 124$126{ }^{\circ} \mathrm{C} .{ }^{1} \mathrm{H} \mathrm{NMR}\left(\mathrm{CDCl}_{3}, 500 \mathrm{MHz}\right) 0.02(\mathrm{~s}, 9 \mathrm{H}), 0.05(\mathrm{~s}, 9 \mathrm{H})$, 0.99-1.05 (m, 4H), 1.21-1.25 (m, 8H), 1.56 (s, 4H), 1.98 (s, 1H), 2.13-2.17 (m, 3H), 2.26-2.34 (m, 8H), 2.57-2.61 (m, 2H), 3.21 (br s, 1H), $3.33(\mathrm{~s}, 1 \mathrm{H}), 3.43-3.50(\mathrm{~m}, 2 \mathrm{H}), 3.94(\mathrm{~s}, 3 \mathrm{H}), 4.20-4.29$ $(\mathrm{m}, 4 \mathrm{H}), 4.58(\mathrm{~s}, 2 \mathrm{H}), 4.65-4.68(\mathrm{~m}, 1 \mathrm{H}), 5.56$ (br s, 1H), $5.97(\mathrm{~s}$, 1H), 6.25 (br s, 1H), 6.59 (br s, 2H), 6.72 (br s, 1H), 6.84 (s, 2H), 6.96-6.97 (m, 2H), 7.12 (br s, 1H), 7.19 (br s, 1H), 7.63-7.64 (m, $2 \mathrm{H}), 8.74(\mathrm{~s}, 1 \mathrm{H}) .{ }^{13} \mathrm{C} \mathrm{NMR}\left(\mathrm{CDCl}_{3}, 125 \mathrm{MHz}\right),-1.5$ (6C), 11.8, 15.3, 16.8, 17.1, 23.8, 25.2, 26.3, 28.2, 28.8, 28.9, 31.7, 35.4, 37.8 (2C), 41.8, 46.1, 52.2, 58.4, 62.4, 63.6, 77.6, 96.2, 110.1, 111.2 (2C), 111.3, 113.0, 121.2, 121.3, 122.4, 122.9, 126.3, 127.4, 128.2, 129.0, 129.6 (2C), 140.6, 142.1, 148.5, $150.7(\times 2), 152.2,155.2$, $155.6,159.4,162.0,166.3,167.3,171.5,172.3,196.6$. HRMS (TOF) $(\mathrm{m} / \mathrm{z}):[(\mathrm{M}+\mathrm{H})]^{+}$calcd for $\mathrm{C}_{58} \mathrm{H}_{81} \mathrm{~N}_{12} \mathrm{O}_{10} \mathrm{Si}_{2}, 1161.5732$; found, 1161.5700 .

Teoc-FA-PEG-prod(C2) (25a). Compound 25a was obtained according to GP2 as an orange-brown solid (0.146 g, 91\%). Mp 114-115 ${ }^{\circ} \mathrm{C} .{ }^{1} \mathrm{H} \mathrm{NMR}\left(\mathrm{CDCl}_{3}, 500 \mathrm{MHz}\right) 0.01(\mathrm{~s}, 9 \mathrm{H}), 0.06(\mathrm{~s}, 9 \mathrm{H})$, 0.96-1.00 (m, 2H), 1.02-1.06 (m, 2H), $1.20(\mathrm{t}, J=7.0 \mathrm{~Hz}, 1 \mathrm{H})$, $1.71(\mathrm{dt}, J=21.5,6.0 \mathrm{~Hz}, 4 \mathrm{H}), 2.10-2.14(\mathrm{~m}, 2 \mathrm{H}), 2.19-2.29(\mathrm{~m}$, $2 \mathrm{H}), 2.33(\mathrm{~s}, 6 \mathrm{H}), 2.49(\mathrm{t}, J=6.7 \mathrm{~Hz}, 2 \mathrm{H}), 2.97(\mathrm{t}, J=6.7 \mathrm{~Hz}, 2 \mathrm{H})$, 3.23-3.32 (m, 4H), 3.46-3.63 (m, 12H), 3.92 (s, 3H), 4.16-4.19 $(\mathrm{m}, 2 \mathrm{H}), 4.28(\mathrm{t}, J=7.7 \mathrm{~Hz}, 2 \mathrm{H}), 4.57-4.64(\mathrm{~m}, 3 \mathrm{H}), 5.38(\mathrm{br} \mathrm{s}$, $1 \mathrm{H}), 5.93(\mathrm{~s}, 1 \mathrm{H}), 6.26(\mathrm{~s}, 1 \mathrm{H}), 6.56(\mathrm{~d}, J=7.2 \mathrm{~Hz}, 2 \mathrm{H}), 6.71(\mathrm{~s}$, $2 \mathrm{H}), 6.78(\mathrm{~s}, 2 \mathrm{H}), 6.96(\mathrm{br} \mathrm{s}, 1 \mathrm{H}), 7.39$ (d, J=6.5 Hz, 1H), 7.67 (d, $J=7.2 \mathrm{~Hz}, 2 \mathrm{H}), 8.74$ (br s, $1 \mathrm{H}) .{ }^{13} \mathrm{C} \mathrm{NMR}\left(\mathrm{CDCl}_{3}, 125 \mathrm{MHz}\right)$, -1.41 (6C), 12.5, 15.4, 17.5, 17.7, 27.7, 29.0, 29.2, 30.4 (2C), 32.9, 37.6, 37.8, 38.1 (2C), 46.7, 53.1, 58.6, 63.9, 65.6, 65.9 (2C), 69.6, 69.7, 70.0, 70.1, 70.5 (2C), 95.5, 110.8, 111.5, 112.1 (2C), 113.9, 122.5 ( $\times 2$ ), 123.8, 126.5, 127.7, 129.2, 129.8 (2C), 142.6, 149.0, $150.4,151.5,154.0,154.7,167.5,168.2,172.7,173.1,196.0$ (2 
carbons uncounted for). HRMS (TOF) $(\mathrm{m} / \mathrm{z})$ : $[\mathrm{M}+\mathbf{H}]^{+}$calcd for $\mathrm{C}_{60} \mathrm{H}_{85} \mathrm{~N}_{12} \mathrm{O}_{13} \mathrm{Si}_{2}, 1237.5892$; found, 1237.5890 .

Teoc-FA-PEG-prod(C4) (25b). Compound 25b was obtained according to GP2 as a dark red solid $(0.101 \mathrm{~g}, 89 \%)$. Mp 128$130{ }^{\circ} \mathrm{C} .{ }^{1} \mathrm{H}$ NMR $\left(\mathrm{CDCl}_{3}, 500 \mathrm{MHz}\right) 0.03$ (s, 9H), 0.07 (s, 9H), 0.98-1.01 (m, 2H), 1.04-1.07 (m, 2H), 1.61 (br s, 4H), 1.70-1.72 (m, 2H), 1.75-1.78 (m, 2H), 2.16-2.22 (m, 4H), 2.30-2.39 (m, $8 \mathrm{H}), 2.61$ (br s, $2 \mathrm{H}), 3.23-3.36(\mathrm{~m}, 4 \mathrm{H}), 3.50-3.60(\mathrm{~m}, 12 \mathrm{H}), 3.94$ (s, 3H), 3.97-3.99 (br m, 1H), 4.18-4.22 (m, 2H), 4.27-4.31 (m, $2 \mathrm{H}), 4.57$ (br s, 2H), 4.61-4.66 (m, 2H), $5.44(\mathrm{br} \mathrm{s}, 1 \mathrm{H}), 5.95(\mathrm{~s}$, $1 \mathrm{H}), 6.27(\mathrm{~s}, 1 \mathrm{H}), 6.58(\mathrm{~d}, 2 \mathrm{H}, J=7.2 \mathrm{~Hz}), 6.72-6.74(\mathrm{~m}, 2 \mathrm{H}), 6.81$ (s, 1H), $6.90(\mathrm{br} \mathrm{s}, 1 \mathrm{H}), 6.97(\mathrm{br} \mathrm{s}, 1 \mathrm{H}), 7.41(\mathrm{~d}, 1 \mathrm{H}, J=7 \mathrm{~Hz}), 7.68$ (d, $2 \mathrm{H}, J=7.2 \mathrm{~Hz}), 8.74$ (br s, $1 \mathrm{H}) .{ }^{13} \mathrm{C} \mathrm{NMR}\left(\mathrm{CDCl}_{3}, 125 \mathrm{MHz}\right)$, -1.5 (6C), 12.3, 15.1, 17.4, 17.6, 23.7, 25.4, 27.7, 28.5, 29.0, 29.2, 29.7, 32.8, 36.5, 37.5, 37.8, 42.3, 46.7, 53.0, 58.6, 63.8, 65.7, 69.7, 70.0, 70.1, 70.4 (2C), 95.6, 110.8, 111.5, 112.1 (2C), 114.0, 122.5, 123.0, 123.6, 126.4, 127.6, 127.9, 129.1, 129.8 (2C), 139.9, 142.2, $149.1,150.3,151.5,154.1,154.6,159.4,161.9,167.5,168.3$, 172.6, 172.7, 173.2, 197.4. HRMS (TOF) $(m / z):[(\mathrm{M}+\mathrm{H}+\mathrm{Na}) / 2]^{2+}$ calcd for $\mathrm{C}_{62} \mathrm{H}_{89} \mathrm{~N}_{12} \mathrm{NaO}_{13} \mathrm{Si}_{2}$, 644.3049; found, 644.3030 .

Teoc-FA-PEG-prod(C8) (25c). Compound 25c was obtained according to GP2. The crude mixture was purified by column chromatography using $\mathrm{Al}_{2} \mathrm{O}_{3}$ type III neutral $\left(\mathrm{CH}_{2} \mathrm{Cl}_{2}: \mathrm{MeOH}\right.$, $9: 1)$ and $25 \mathrm{c}$ was obtained as dark red glass $(0.065 \mathrm{~g}, 47 \%) .{ }^{1} \mathrm{H}$ NMR $\left(\mathrm{CDCl}_{3}, 500 \mathrm{MHz}\right) 0.01(\mathrm{~s}, 9 \mathrm{H}), 0.05(\mathrm{~s}, 9 \mathrm{H}), 0.82-0.89(\mathrm{~m}$, 1H), 0.96-1.07 (m, 4H), 1.25 (br s, 8H), 1.57-1.58 (br m, 4H), 1.68-1.77 (m, 4H), 2.09-2.14 (m, 2H), 2.19-2.25 (m, 2H), 2.29$2.33(\mathrm{~m}, 2 \mathrm{H}), 2.36(\mathrm{~s}, 6 \mathrm{H}), 2.61(\mathrm{t}, 2 \mathrm{H}, J=7.1 \mathrm{~Hz}), 3.27-3.34(\mathrm{~m}$, $4 \mathrm{H}), 3.47-3.58(\mathrm{~m}, 12 \mathrm{H}), 3.94(\mathrm{~s}, 3 \mathrm{H}), 4.17-4.22(\mathrm{~m}, 2 \mathrm{H}), 4.26-$ $4.31(\mathrm{~m}, 2 \mathrm{H}), 4.62(\mathrm{br} \mathrm{s}, 3 \mathrm{H}), 5.43(\mathrm{br} \mathrm{s}, 1 \mathrm{H}), 5.98(\mathrm{~s}, 1 \mathrm{H}), 6.24$ (br s, $1 \mathrm{H}), 6.44-6.48(\mathrm{~m}, 1 \mathrm{H}), 6.60(\mathrm{~d}, 2 \mathrm{H}, J=8.3 \mathrm{~Hz}), 6.72(\mathrm{br} \mathrm{s}$, $1 \mathrm{H}), 6.81-6.85(\mathrm{~m}, 2 \mathrm{H}), 6.90(\mathrm{br} \mathrm{s}, 1 \mathrm{H}), 7.40(\mathrm{~d}, 1 \mathrm{H}, J=7.2 \mathrm{~Hz})$, $7.67(\mathrm{~d}, 2 \mathrm{H}, J=8.3 \mathrm{~Hz}), 8.77(\mathrm{~s}, 1 \mathrm{H}) .{ }^{13} \mathrm{C} \mathrm{NMR}\left(\mathrm{CDCl}_{3}, 125 \mathrm{MHz}\right)$, -1.4 (6C), 12.4, 15.2, 17.5, 17.7, 24.3, 25.9, 27.9, 29.0, $29.3(\times 2)$, 29.4, $29.5(\times 2), 29.8$ (2C), 32.9, 36.9, 37.7, 38.0 (2C), 42.8, 46.9, 53.1, 58.7, 64.0, 66.1 (2C), 69.9, 70.0, 70.1, 70.2, 70.6, 95.7, 110.9, 111.9, 112.3 (2C), 114.0, 122.8, 123.5, 126.6, 127.9, 129.2, 130.1 (2C), 140.2, 142.2, 149.4, 150.3, 151.8, 154.0, 154.8, 159.6, 161.0, 167.3, 168.5, 172.6, 172.7, 173.5, 198.1. HRMS (TOF) $(\mathrm{m} / \mathrm{z})$ : [M + $\mathrm{H}]^{+}$calcd for $\mathrm{C}_{66} \mathrm{H}_{97} \mathrm{~N}_{12} \mathrm{O}_{13} \mathrm{Si}_{2}, 1321.6831$; found, 1321.6807 .

Teoc-FA-SS-prod(C2) (26a). Compound 26a was obtained according to GP2 as an orange-brown solid $(0.042 \mathrm{~g}, 54 \%)$. Mp 149-151 ${ }^{\circ} \mathrm{C} .{ }^{1} \mathrm{H}$ NMR $\left(\mathrm{CDCl}_{3}, 500 \mathrm{MHz}\right) 0.00(1 \mathrm{~s}, 9 \mathrm{H}), 0.04(\mathrm{~s}$, $9 \mathrm{H}), 0.95(\mathrm{t}, J=8.5 \mathrm{~Hz}, 2 \mathrm{H}), 1.01(\mathrm{t}, J=8.5 \mathrm{~Hz}, 2 \mathrm{H}), 1.25(\mathrm{~s}, 1 \mathrm{H})$, 2.16-2.20 (m, 2H), $2.26(\mathrm{~s}, 6 \mathrm{H}), 2.33-2.39(\mathrm{~m}, 2 \mathrm{H}), 2.45$ (br s, $2 \mathrm{H}), 2.61$ (br s, 2H), 2.71-2.72 (m, 2H), 2.92 (br s, 2H), 3.42-3.51 (m, 4H), $3.91(\mathrm{~s}, 3 \mathrm{H}), 4.15(\mathrm{t}, J=8.5 \mathrm{~Hz}, 2 \mathrm{H}), 4.24-4.32(\mathrm{~m}, 3 \mathrm{H})$, 4.55 (br s, 2H), 4.65-4.68 (m, 1H), 5.49 (br s, 1H), $5.92(\mathrm{~s}, 1 \mathrm{H})$, $6.23(\mathrm{~s}, 1 \mathrm{H}), 6.53(\mathrm{~d}, J=7.7 \mathrm{~Hz}, 2 \mathrm{H}), 6.69(\mathrm{~s}, 1 \mathrm{H}), 6.72(\mathrm{~s}, 1 \mathrm{H})$, $6.91(\mathrm{~s}, 1 \mathrm{H}), 7.06(\mathrm{br} \mathrm{s}, 1 \mathrm{H}), 7.36(\mathrm{br} \mathrm{s}, 1 \mathrm{H}), 7.64(\mathrm{~d}, J=7.7 \mathrm{~Hz}$, $2 \mathrm{H}), 8.71(\mathrm{~s}, 1 \mathrm{H}) .{ }^{13} \mathrm{C} \mathrm{NMR}\left(\mathrm{CDCl}_{3}, 125 \mathrm{MHz}\right),-1.4(6 \mathrm{C}), 12.5$, 15.6, 17.5, 17.7, 27.5, 28.5, 29.8, 30.3, 32.8 (2C), 38.0 (2C), 38.7, $38.8,46.8,53.1,58.6,64.0,65.9,95.4,110.9,111.3,112.1,112.2$ (2C), 114.1, 122.4, 124.0, 126.5 (2C), 127.5, 129.2 (2C), 130.0, 142.9, 149.1, 150.4, 151.9, 154.1, 167.6, 168.1, 172.6, 173.2, 173.6, 196.0 ( 3 carbon atoms unaccounted for). HRMS (TOF) $(\mathrm{m} /$
$z):[(\mathrm{M}+\mathrm{H}+\mathrm{Na}) / 2]^{2+}$ calcd for $\mathrm{C}_{54} \mathrm{H}_{73} \mathrm{~N}_{12} \mathrm{Na}_{1} \mathrm{O}_{10} \mathrm{~S}_{2} \mathrm{Si}_{2}, 596.2211$; found, 596.2220.

Teoc-FA-SS-prod(C4) (26b). A solution of $4 \mathbf{b}(0.128 \mathrm{~g}, 0.203$ $\mathrm{mmol})$ in a mixture of $\mathrm{MeOH}: \mathrm{CHCl}_{3}(1: 1,4 \mathrm{~mL})$ was treated with $\mathrm{HCl} 12 \mathrm{~N}(1.2 \mathrm{~mL}, 14.4 \mathrm{mmol})$ and the reaction mixture was stirred at room temperature for $4 \mathrm{~h}$. The solvent was removed under reduced pressure to obtain $\mathbf{4 b}$ as dark purple solid $(0.124$ $\mathrm{g})$, which was used in the next step without any further purification. HRMS (TOF) $\left(\mathrm{m} / \mathrm{z}\right.$ ): $[\mathrm{M}+\mathrm{H}]^{+}$calcd for $\mathrm{C}_{26} \mathrm{H}_{36} \mathrm{~N}_{5} \mathrm{O}_{3} \mathrm{~S}_{2}$, 530.2254; found, 530.2264. Compound 26b was obtained according to GP2. The crude mixture was purified by column chromatography using $\mathrm{Al}_{2} \mathrm{O}_{3}$ type III neutral $\left(\mathrm{CH}_{2} \mathrm{Cl}_{2}: \mathrm{MeOH}\right.$, $9: 1)$ and $26 \mathbf{b}$ was obtained as an orange solid $(0.176 \mathrm{~g}, 72 \%)$. Mp $135-137^{\circ} \mathrm{C} .{ }^{1} \mathrm{H}$ NMR $\left(\mathrm{CDCl}_{3}, 500 \mathrm{MHz}\right) 0.02(\mathrm{~s}, 9 \mathrm{H}), 0.06$ (s, 9H), 0.81-0.90 (m, 1H), 0.96-1.06 (m, 4H), 1.58 (br s, 4H), 2.09$2.19(\mathrm{~m}, 4 \mathrm{H}), 2.26(\mathrm{br} \mathrm{m}, 3 \mathrm{H}), 2.31(\mathrm{~s}, 3 \mathrm{H}), 2.34-2.40(\mathrm{~m}, 2 \mathrm{H})$, 2.57 (br s, $2 \mathrm{H}), 2.69-2.78(\mathrm{~m}, 4 \mathrm{H}), 3.40-3.53(\mathrm{~m}, 4 \mathrm{H}), 3.93(\mathrm{~s}$, $3 \mathrm{H}), 4.16-4.32(\mathrm{~m}, 4 \mathrm{H}), 4.58(\mathrm{~d}, 2 \mathrm{H}, J=4.0 \mathrm{~Hz}), 4.65-4.72(\mathrm{~m}$, $1 \mathrm{H}), 5.45-5.46(\mathrm{~m}, 1 \mathrm{H}), 5.95(\mathrm{~s}, 1 \mathrm{H}), 6.25-6.27(\mathrm{~m}, 1 \mathrm{H}), 6.56(\mathrm{~d}$, $2 \mathrm{H}, J=8.6 \mathrm{~Hz}), 6.72(\mathrm{br} \mathrm{s}, 1 \mathrm{H}), 6.80(\mathrm{~s}, 1 \mathrm{H}), 6.89-6.95(\mathrm{~m}, 2 \mathrm{H})$, $7.14(\mathrm{t}, 1 \mathrm{H}, J=5.6 \mathrm{~Hz}), 7.32(\mathrm{~d}, 1 \mathrm{H}, J=6.7 \mathrm{~Hz}), 7.65(\mathrm{~d}, 2 \mathrm{H}, J=$ $8.6 \mathrm{~Hz}), 8.75(\mathrm{~s}, 1 \mathrm{H}) .{ }^{13} \mathrm{C} \mathrm{NMR}\left(\mathrm{CDCl}_{3}, 125 \mathrm{MHz}\right),-1.4(6 \mathrm{C}), 12.4$, 15.4, 17.5, 17.7, 23.6, 25.3, 27.3, 29.8, 32.9, 36.4, 37.9, 38.1, 38.6, $38.8,42.2,46.8,53.0,58.7,64.0,66.0,95.6,111.0,111.6,112.2$ (2C), 114.2, 122.5, 123.1, 124.0, 126.5, 127.5, 129.2 (2C), 129.9, $139.8,142.3,149.2,149.9,150.4,151.8,154.0,154.7,159.3$, 161.5, 167.7, 168.3, 172.6, 173.2, 173.8, 197.5. HRMS (TOF) $(\mathrm{m} /$ z): $[(\mathrm{M}+\mathrm{H}+\mathrm{Na}) / 2]^{+}$calcd for $\mathrm{C}_{56} \mathrm{H}_{77} \mathrm{~N}_{12} \mathrm{NaO}_{10} \mathrm{~S}_{2} \mathrm{Si}_{2}, 610.2376$; found, 610.2356 .

Teoc-FA-SS-prod(C8) (26c). A solution of $4 \mathrm{c}(0.150 \mathrm{~g}, 0.22$ $\mathrm{mmol})$ in a mixture of $\mathrm{MeOH}: \mathrm{CHCl}_{3}(1: 1,4 \mathrm{~mL})$ was treated with $\mathrm{HCl} 12 \mathrm{~N}(0.036 \mathrm{~mL}, 0.44 \mathrm{mmol})$. After an additional $30 \mathrm{~min} \mathrm{HCl} 12 \mathrm{~N}(0.030 \mathrm{~mL}, 0.36 \mathrm{mmol})$ was added and the reaction mixture stirred for a further 12 hours. The solvent was removed under reduced pressure to afford $4 \mathbf{c}$ as a red glass $(0.130 \mathrm{~g})$, which was used in the next step without any further purification. HRMS (TOF) $(\mathrm{m} / \mathrm{z}):[\mathrm{M}+\mathrm{H}]^{+}$calcd for $\mathrm{C}_{30} \mathrm{H}_{44} \mathrm{~N}_{5} \mathrm{O}_{3} \mathrm{~S}_{2}, 586.2880$; found, 586.2856. Compound 26c was obtained according to $\mathrm{GP} 2$ as a dark red glass $(0.086 \mathrm{~g}, 69 \%) .{ }^{1} \mathrm{H}$ $\mathrm{NMR}\left(\mathrm{CDCl}_{3}, 500 \mathrm{MHz}\right) 0.00(\mathrm{~s}, 9 \mathrm{H}), 0.04(\mathrm{~s}, 9 \mathrm{H}), 0.96-1.00(\mathrm{~m}$, $4 \mathrm{H}), 1.02-1.04(\mathrm{~m}, 8 \mathrm{H}), 1.21-1.24(\mathrm{~m}, 4 \mathrm{H}), 1.53-1.55(\mathrm{~m}, 4 \mathrm{H})$, 2.10-2.13 (m, 3H), 2.21 (app br s, $4 \mathrm{H}), 2.34-2.36(\mathrm{~m}, 5 \mathrm{H}), 2.57-$ $2.58(\mathrm{~m}, 2 \mathrm{H}), 2.68-2.69(\mathrm{~m}, 2 \mathrm{H}), 2.72-2.75(\mathrm{~m}, 2 \mathrm{H}), 3.40-3.52$ $(\mathrm{m}, 4 \mathrm{H}), 3.92(\mathrm{~m}, 3 \mathrm{H}), 4.17-4.20(\mathrm{~m}, 2 \mathrm{H}), 4.26(\mathrm{t}, J=8.2 \mathrm{~Hz}, 2 \mathrm{H})$, $4.58(\mathrm{~s}, 2 \mathrm{H}), 4.64-4.68(\mathrm{~m}, 1 \mathrm{H}), 5.59(\mathrm{br} \mathrm{s}, 1 \mathrm{H}), 5.97(\mathrm{~s}, 1 \mathrm{H}), 6.21$ $(\mathrm{s}, 1 \mathrm{H}), 6.56(\mathrm{~d}, J=7.5 \mathrm{~Hz}, 2 \mathrm{H}), 6.70(\mathrm{~s}, 2 \mathrm{H}), 6.83(\mathrm{~s}, 2 \mathrm{H}), 7.25-$ $7.26(\mathrm{~m}, 2 \mathrm{H}), 7.35(\mathrm{~d}, J=6.0 \mathrm{~Hz}, 1 \mathrm{H}), 7.62(\mathrm{~d}, J=7.5 \mathrm{~Hz}, 2 \mathrm{H})$, $8.74(\mathrm{~s}, 1 \mathrm{H}) .{ }^{13} \mathrm{C}$ NMR $\left(\mathrm{CDCl}_{3}, 125 \mathrm{MHz}\right),-1.4(6 \mathrm{C}), 12.4,14.9$, 17.5, 17.7, 24.3, 25.8, 28.1, 29.1, 29.2, $29.4(\times 2), 32.8,36.6,37.9$, 38.0, 38.6, 42.8, 46.9, 52.9, 58.7, 64.1, 66.0, 95.7, 110.9, 111.8, 112.2 (2C), 114.0, 122.5, 123.4, 123.8, 126.4, 127.7, 129.2 (2C), 130.0, 139.9, 142.1, 149.3, 149.8, 150.4, 151.8, 154.1, 154.8, 159.8, 161.3, 167.6, 168.5, 168.6, 172.6, 173.2, 174.0, 198.1 (1 carbon atom unaccounted for). HRMS (TOF) $(\mathrm{m} / \mathrm{z})$ : [(M $+\mathrm{H}+$ $\mathrm{Na}) / 2]^{2+}$ calcd for $\mathrm{C}_{60} \mathrm{H}_{85} \mathrm{~N}_{12} \mathrm{Na}_{1} \mathrm{O}_{10} \mathrm{~S}_{2} \mathrm{Si}_{2}, 638.2689$; found, 638.2663 . 


\section{General procedure 3 (GP3)}

A solution of (1 eq.) Teoc-FA-LINKERS-prod. (1 eq.) in anhydrous DMSO (0.1 M) was treated with TBAF (1 M solution in THF, 2 eq.) and $\mathrm{AcOH}(1.25 / 0.1 \mathrm{mmol})$. The resulting reaction mixture was stirred at room temperature for $18 \mathrm{~h}$ under $\mathrm{N}_{2}$ atmosphere. EtOAc was added to the reaction mixture until a precipitate formed, which was filtered using Milipore ${ }^{\circledR}$ and washed 3 times with water. The obtained dark red solid was dissolved in DMSO (0.1 M), treated with $\mathrm{NaOH}(0.2 \mathrm{M}$ solution in $\mathrm{MeOH}$ ) and stirred at room temperature for $10 \mathrm{~min}$. Water was added and a precipitate was formed. The resulting sodium salt was isolated via microfiltration, then washed 3 times with water and dried under vacuum.

FA-DA-prod(C2) (27a). Compound 27a was obtained according to GP3 as dark red solid (0.040 g, 53\%). Mp decomp. $>230{ }^{\circ} \mathrm{C} .{ }^{1} \mathrm{H}$ NMR $\left(\mathrm{DMSO}_{6}, 500 \mathrm{MHz}, 80^{\circ} \mathrm{C}\right) 1.39(\mathrm{~s}, 3 \mathrm{H}), 1.96-$ $2.22(\mathrm{~m}, 7 \mathrm{H}), 2.68(\mathrm{~s}, 3 \mathrm{H}), 3.00(\mathrm{~s}, 4 \mathrm{H}), 3.90(\mathrm{~s}, 3 \mathrm{H}), 4.32(\mathrm{br} \mathrm{s}$, 1H), 4.49 (s, 2H), 6.16 (br s, 1H), 6.26 (br s, 1H), 6.67 (br s, 4H), 6.78 (br s, 1H), 7.09 (br s, 1H), 7.64 (br s, 3H), 7.90 (br s, 1H), 8.65 (br s, 1H), 11.61 (br s, $1 \mathrm{H}) .{ }^{13} \mathrm{C}$ NMR (DMSO-d $\left.6,125 \mathrm{MHz}\right) 11.8$, 15.4, 26.8, 28.2, 29.4, 32.0, 36.6, 37.3, 38.4 (2C), 45.9, 52.3, 58.4, 96.3, 110.2, 111.2 (2C), 113.1, 121.4, 122.1, 122.9, 127.6, 127.9, 128.2, 128.9 (2C), 140.9, 142.0, 148.5, 150.7, 153.9, 155.6, 156.3, $159.4,161.2,166.3,167.4,171.8,174.0,195.3$ (1 carbon uncounted for). HRMS (TOF) $(\mathrm{m} / \mathrm{z}):[(\mathrm{M}-\mathrm{H}-\mathrm{Na}) / 2]^{2-}$ calcd for $\mathrm{C}_{41} \mathrm{H}_{42} \mathrm{NaN}_{12} \mathrm{O}_{8}, 415.1630$; found, 415.1648.

FA-DA-prod(C4) (27b). Compound 27b was obtained according to GP3 as dark red solid (0.036 g, 68\%). Mp decomp. $>200{ }^{\circ} \mathrm{C}$. ${ }^{1} \mathrm{H}$ NMR (DMSO-d $6,500 \mathrm{MHz}, 60{ }^{\circ} \mathrm{C}$ ) 1.54 (br s, 4H), 1.85-1.95 (m, 2H), 2.08-2.27 (m, 6H), $2.34(\mathrm{~s}, 3 \mathrm{H}), 2.68(\mathrm{~s}, 3 \mathrm{H})$, 2.73 (br s, 2H), 3.06 (br s, 4H), 3.87 (s, 3H), 4.23-4.31 (m, 1H), 4.47 (d, 2H, $J=5.6 \mathrm{~Hz}), 6.19(\mathrm{~s}, 1 \mathrm{H}), 6.24(\mathrm{br} \mathrm{s}, 1 \mathrm{H}), 6.64(\mathrm{~d}, 2 \mathrm{H}, J$ $=8.6 \mathrm{~Hz}), 6.69(\mathrm{~s}, 1 \mathrm{H}), 6.78-6.79(\mathrm{~m}, 1 \mathrm{H}), 6.87-6.91(\mathrm{~m}, 2 \mathrm{H})$, 6.78 (br s, 1H), 7.13 (br s, $1 \mathrm{H}), 7.65$ (d, 2H, J = 8.4 Hz), 7.79-7.85 $(\mathrm{m}, 2 \mathrm{H}), 8.15(\mathrm{~d}, 1 \mathrm{H}, J=5.4 \mathrm{~Hz}), 8.63(\mathrm{~s}, 1 \mathrm{H}), 11.81$ (br s, $1 \mathrm{H}) \cdot{ }^{13} \mathrm{C}$ NMR (DMSO-d 6 , 125 MHz) 11.8, 15.3, 23.4, 24.9, 26.6, 28.2, 32.0, 35.5, 38.3, 38.5, 41.6, 45.9, 52.1, 58.4, 96.3, 110.2, 111.2 (2C), $113.1,121.4,122.3,122.9,126.3,127.6,127.9,128.2,128.9$ (2C), $140.8,142.1,148.5,150.8,153.8,156.3$, 159.3, 161.0, 161.1, $166.3,167.4,171.7,172.2,173.9,196.3$. HRMS (TOF) $(\mathrm{m} / \mathrm{z}):[\mathrm{M}-$ $\mathrm{H}-\mathrm{Na} / 2]^{2-}$ calcd for $\mathrm{C}_{43} \mathrm{H}_{46} \mathrm{NaN}_{12} \mathrm{O}_{8}, 429.1786$; found, 429.1796.

FA-DA-prod(C8) (27c). Compound 27c was obtained according to GP3 as a black solid (0.025 g, 67\%). Mp decomp. $>205{ }^{\circ} \mathrm{C}$. ${ }^{1} \mathrm{H}$ NMR (DMSO-d 6 , $500 \mathrm{MHz}$ ) 1.24-1.27 (m, 8H), 1.45-1.48 (m, $2 \mathrm{H})$, 1.55-1.57 (m, 2H), 1.88-1.93 (m, 1H), 2.01-2.09 (m, 3H), 2.15-2.19 (m, 2H), $2.34(\mathrm{~s}, 3 \mathrm{H}), 2.67(\mathrm{~s}, 3 \mathrm{H}), 2.72(\mathrm{t}, 2 \mathrm{H}, J=7.0$ $\mathrm{Hz}$ ), 3.00-3.10 (m, 5H), 3.30 (br s, $4 \mathrm{H}), 3.87$ (s, 3H), 4.28-4.30 (m, $1 \mathrm{H}), 4.48(\mathrm{~d}, 2 \mathrm{H}, J=5.5 \mathrm{~Hz}), 6.19(\mathrm{~s}, 1 \mathrm{H}), 6.24(\mathrm{~s}, 1 \mathrm{H}), 6.64(\mathrm{~d}$, $2 \mathrm{H}, J=8.2 \mathrm{~Hz}), 6.69(\mathrm{~s}, 1 \mathrm{H}), 6.79(\mathrm{~s}, 1 \mathrm{H}), 6.89-6.91(\mathrm{~m}, 2 \mathrm{H}), 7.14$ $(\mathrm{s}, 1 \mathrm{H}), 7.65(\mathrm{~d}, 2 \mathrm{H}, J=8.2 \mathrm{~Hz}), 7.74(\mathrm{~s}, 1 \mathrm{H}), 7.84(\mathrm{~s}, 1 \mathrm{H}), 8.17$ (d, $1 \mathrm{H}, J=7.5 \mathrm{~Hz}), 8.64(\mathrm{~s}, 1 \mathrm{H}), 11.43(\mathrm{~s}, 1 \mathrm{H}), 11.81(\mathrm{~s}, 1 \mathrm{H}) .{ }^{13} \mathrm{C} \mathrm{NMR}$ (DMSO-d 6 , $125 \mathrm{MHz})$ 11.7, 15.3, 23.7, 25.1, 27.0, 28.2, $28.7(\times 2)$, 28.9, 32.0, 35.4, 41.8, 45.9, 52.3, 58.4, 77.5, 96.2, 110.1, 111.2 (2C), 113.0, 121.5, 122.4, 122.9, 126.3, 127.5, 127.9, 128.2, 128.8 (2C), 140.7, 142.0, 148.5, 150.7, 154.0, 155.6, 156.2, 159.3, 161.2, $166.1,167.3,171.8,172.3,173.0,174.2$, 196.6 (1 carbon uncounted for). HRMS (TOF) $(\mathrm{m} / \mathrm{z}):[(\mathrm{M}+\mathrm{H}-\mathrm{Na})]^{+}$calcd for $\mathrm{C}_{47} \mathrm{H}_{55} \mathrm{NaN}_{12} \mathrm{O}_{8}$, 915.4271; found, 915.4232.

FA-PEG-prod(C4) (28a). Compound 28a was obtained according to GP3 as a black solid $(0.010 \mathrm{~g}, 41 \%)$. Mp $185{ }^{\circ} \mathrm{C} .{ }^{1} \mathrm{H}$ NMR (DMSO-d 6 , $500 \mathrm{MHz}$ ) 1.57-1.63 (m, 4H), 1.86-1.93 (m, 1H), 2.01-2.07 (m, 1H), $2.17(\mathrm{t}, 2 \mathrm{H}, J=7.5 \mathrm{~Hz}), 2.35(\mathrm{~s}, 3 \mathrm{H}), 2.40(\mathrm{t}$, $2 \mathrm{H}, J=6.7 \mathrm{~Hz}), 2.69(\mathrm{~s}, 3 \mathrm{H}), 2.97(\mathrm{t}, 2 \mathrm{H}, J=6.7 \mathrm{~Hz}), 3.04-3.10$ (m, 4H), 3.34-3.50 (m, 12H), $3.87(\mathrm{~s}, 3 \mathrm{H}), 4.24-4.28(\mathrm{~m}, 1 \mathrm{H}), 4.48$ $(\mathrm{d}, 2 \mathrm{H}, J=5.5 \mathrm{~Hz}), 6.19(\mathrm{~s}, 1 \mathrm{H}), 6.24(\mathrm{~s}, 1 \mathrm{H}), 6.64(\mathrm{~d}, 2 \mathrm{H}, J=8.7$ $\mathrm{Hz}), 6.70(\mathrm{~s}, 1 \mathrm{H}), 6.79(\mathrm{~s}, 1 \mathrm{H}), 6.88-6.90(\mathrm{~m}, 2 \mathrm{H}), 7.13(\mathrm{~s}, 1 \mathrm{H})$, $7.64(\mathrm{~d}, 2 \mathrm{H}, J=8.7 \mathrm{~Hz}), 7.78-7.81(\mathrm{~m}, 2 \mathrm{H}), 8.12(\mathrm{~d}, 1 \mathrm{H}, J=7.0$ $\mathrm{Hz}), 8.64$ (s, 1H), 11.82 (br s, 1H). ${ }^{13} \mathrm{C} \mathrm{NMR}\left(\mathrm{DMSO}_{6}, 125 \mathrm{MHz}\right)$ 11.8, 15.4, 26.6, 29.3, 29.4 (2C), 32.0, 35.8, 37.3 (2C), 45.9, 52.3, 58.4, 68.0 (2C), 68.1, 69.5, 69.7 (4C), 96.3, 110.1, $111.2(2 \mathrm{C})$, $113.1,121.4,122.1,122.9,126.3,127.6,127.9,128.2,128.9$ (2C), $140.8,142.1$, 148.5, 150.7, 153.8, 159.4, 166.2, 167.4, 171.5, 173.9, 195.3 (3 carbon atoms unaccounted for). HRMS (TOF) $(\mathrm{m} /$ $z):[(\mathrm{M}-\mathrm{H}-\mathrm{Na}) / 2]^{2-}$ calcd for $\mathrm{C}_{49} \mathrm{H}_{58} \mathrm{NaN}_{12} \mathrm{O}_{11}, 495.2179$; found, 495.2177.

FA-PEG-prod(C4) (28b). Compound 28b was obtained according to GP3 as dark red solid (0.065 g, 79\%). Mp decomp. $>170{ }^{\circ} \mathrm{C} .{ }^{1} \mathrm{H}$ NMR (DMSO-d 6 , $500 \mathrm{MHz}$ ) 1.55-1.64 (m, 8H), 1.89$1.93(\mathrm{~m}, 1 \mathrm{H}), 2.02-2.10(\mathrm{~m}, 3 \mathrm{H}), 2.15-2.19(\mathrm{~m}, 2 \mathrm{H}), 2.35(\mathrm{~s}, 3 \mathrm{H})$, $2.68(\mathrm{~s}, 3 \mathrm{H}), 2.73$ (br s, 2H), 3.02-3.10 (m, 4H), $3.36(\mathrm{dd}, 4 \mathrm{H}, J=$ 12.6, $6.3 \mathrm{~Hz}), 3.45-3.48(\mathrm{~m}, 8 \mathrm{H}), 3.87(\mathrm{~s}, 3 \mathrm{H}), 4.23-4.30(\mathrm{~m}, 1 \mathrm{H})$, $4.48(\mathrm{~d}, 2 \mathrm{H}, J=5.7 \mathrm{~Hz}), 6.19(\mathrm{~s}, 1 \mathrm{H}), 6.24(\mathrm{br} \mathrm{s}, 1 \mathrm{H}), 6.64(\mathrm{~d}, 2 \mathrm{H}, J$ $=8.6 \mathrm{~Hz}), 6.70(\mathrm{~s}, 1 \mathrm{H}), 6.80(\mathrm{br} \mathrm{s}, 1 \mathrm{H}), 6.88-6.91(\mathrm{~m}, 2 \mathrm{H}), 7.13(\mathrm{~s}$, $1 \mathrm{H}), 7.65(\mathrm{~d}, 2 \mathrm{H}, J=8.6 \mathrm{~Hz}), 7.73-7.80(\mathrm{~m}, 2 \mathrm{H}), 8.14(\mathrm{~d}, 1 \mathrm{H}, J=$ $7.4 \mathrm{~Hz}$ ), 8.64 (s, 1H), 11.81 (br s, 1H). ${ }^{13} \mathrm{C}$ NMR (DMSO-d 6 , 125 MHz) 11.8, 15.33, 23.5, 25.1, 26.7, 29.3, 29.4 (2C), 32.0, 35.5, 35.7, 35.8 (2C), 41.2, 41.6, 45.9, 58.4, 68.0 (2C), 68.1, 69.5, 69.7 (4C), 96.3, 110.2, 111.2 (2C), 113.1, 121.4, 122.3, 122.9, 126.3, 128.2, 128.9 (2C), 140.8, 142.1, 148.5, 148.6, 150.7, 153.8, 159.4, 161.0, 166.2, 167.4 171.5, 172.0, 173.9, 196.5. HRMS (TOF) $(\mathrm{m} /$ $z):[\mathrm{M}-\mathrm{Na}]^{-}$calcd for $\mathrm{C}_{51} \mathrm{H}_{63} \mathrm{NaN}_{12} \mathrm{O}_{11}, 1019.4745$; found, 1019.4718.

FA-PEG-prod(C8) (28c). Compound 28c was obtained according to GP3 as dark red solid (0.021 g, 38\%). Mp decomp. $>150{ }^{\circ} \mathrm{C}$. ${ }^{1} \mathrm{H}$ NMR (DMSO-d 6 , $500 \mathrm{MHz}$ ) 1.25-1.26 (br m, 8H), 1.44-1.50 (m, 2H), 1.53-1.64 (m, 4H), $2.03(\mathrm{t}, 2 \mathrm{H}, J=7.1 \mathrm{~Hz})$, 2.14-2.28 (m, 4H), $2.34(\mathrm{~s}, 3 \mathrm{H}), 2.67(\mathrm{~s}, 3 \mathrm{H}), 2.72(\mathrm{t}, 2 \mathrm{H}, J=7.1$ $\mathrm{Hz}), 3.06$ (dd, $4 \mathrm{H}, J=12.9,6.8 \mathrm{~Hz}), 3.33-3.39(\mathrm{~m}, 4 \mathrm{H}), 3.43-3.49$ $(\mathrm{m}, 8 \mathrm{H}), 3.87(\mathrm{~s}, 3 \mathrm{H}), 4.22-4.29(\mathrm{~m}, 1 \mathrm{H}), 4.48(\mathrm{~d}, 2 \mathrm{H}, J=5.7 \mathrm{~Hz})$, $6.19(\mathrm{~s}, 1 \mathrm{H}), 6.64(\mathrm{~d}, 2 \mathrm{H}, J=8.3 \mathrm{~Hz}), 6.69(\mathrm{~s}, 1 \mathrm{H}), 6.78-6.80(\mathrm{~m}$, $1 \mathrm{H}), 6.85-6.92(\mathrm{~m}, 3 \mathrm{H}), 7.13$ (br s, $1 \mathrm{H}), 7.64$ (d, $2 \mathrm{H}, J=8.3 \mathrm{~Hz}$ ), 7.69-7.72 (m, 1H), 7.77-7.81 (m, 1H), 8.14 (d, 1H, $J=7.0 \mathrm{~Hz}$ ), 8.64 (s, 1H), 11.43 (br s, 1H), 11.81 (br s, $1 \mathrm{H}$ ). ${ }^{13} \mathrm{C}$ NMR (DMSO$\left.\mathrm{d}_{6}, 125 \mathrm{MHz}\right) 11.8,15.3,23.8,25.3,26.7,28.6,28.7,28.8,29.0$, 29.3, 29.4, 32.0, 35.4, 35.7, 35.8, 41.8, 45.9, 52.3, 58.4, 68.0, 68.1, $69.5(\times 2), 69.7$ (4C), 96.3, 110.2, $111.2(2 \mathrm{C}), 113.1,121.4,122.4$, 122.9, 126.3, 127.5, 127.9, 128.2, 128.9 (2C), 140.7, 142.1, 148.5, $148.6,150.7,153.8,153.9,159.4,166.2,167.4,171.5,172.0$, 173.8, 197.7. HRMS (TOF) $(\mathrm{m} / \mathrm{z}):[(\mathrm{M}-\mathrm{H}-\mathrm{Na}) / 2]^{-}$calcd for $\mathrm{C}_{55} \mathrm{H}_{70} \mathrm{NaN}_{12} \mathrm{O}_{11}, 537.2649$; found, 537.2664.

FA-SS-prod(C4) (29a). Compound 29a was obtained according to GP3 as a dark red solid $(0.009 \mathrm{~g}, 26 \%) .{ }^{1} \mathrm{H}$ NMR (DMSO$\left.\mathrm{d}_{6}, 300 \mathrm{MHz}, 50{ }^{\circ} \mathrm{C}\right)$ 1.86-1.96 (m, 1H), 2.03-2.17 (m, 1H), 2.19- 
$2.23(\mathrm{~m}, 2 \mathrm{H}), 2.35(\mathrm{~s}, 3 \mathrm{H}), 2.42(\mathrm{t}, 2 \mathrm{H}, J=6.6 \mathrm{~Hz}), 2.68(\mathrm{~s}, 3 \mathrm{H})$, 2.72-2.96 (m, 4H), $3.00(\mathrm{t}, 1 \mathrm{H}, J=7.0 \mathrm{~Hz}), 3.30-3.36(\mathrm{~m}, 5 \mathrm{H})$, 3.89 (s, 3H), 4.29 (br s, 1H), 4.49 (d, 1H, J=4.5 Hz), $6.20(\mathrm{~s}, 1 \mathrm{H})$, $6.25(\mathrm{~s}, 1 \mathrm{H}), 6.62-6.70(\mathrm{~m}, 3 \mathrm{H}), 6.89-6.93(\mathrm{~m}, 3 \mathrm{H}), 7.04-7.07(\mathrm{~m}$, $1 \mathrm{H}), 7.13(\mathrm{~s}, 1 \mathrm{H}), 7.65(\mathrm{~d}, 2 \mathrm{H}, J=7.5 \mathrm{~Hz}), 8.06(\mathrm{t}, 1 \mathrm{H}, J=5.7 \mathrm{~Hz})$, 8.15-8.17 (m, 1H), $8.64(\mathrm{~s}, 1 \mathrm{H}), 11.82$ (br s, $1 \mathrm{H}) .{ }^{13} \mathrm{C}$ NMR (DMSO-d 6 , $125 \mathrm{MHz})$ 11.8, 15.4, 26.5, 28.2, 29.3, 31.9, 37.2 (2C), 37.3, 37.9, 38.1 (2C), 39.0, 45.9, 52.1, 58.4, 96.3, 110.1 (2C), 111.1, 113.1, 121.3, 122.1, 122.9, 126.3, 127.6, 127.9, 128.1, 128.9 (2C), 140.9, 142.0, 148.6, 150.7, 153.8, 159.3, 166.2, 167.3, 171.7 $(\times 2), 173.8,195.1$ (1 carbon atom unaccounted for). HRMS (TOF) $(\mathrm{m} / \mathrm{z}):[(\mathrm{M}-\mathrm{H}-\mathrm{Na}) / 2]^{2-}$ calcd for $\mathrm{C}_{43} \mathrm{H}_{46} \mathrm{NaN}_{12} \mathrm{O}_{8} \mathrm{~S}_{2}$, 461.1507; found, 461.1530.

FA-SS-prod(C4) (29b). Compound 29b was obtained according to GP3 as dark red solid (0.047 g, 30\%). Mp decomp. $>210{ }^{\circ} \mathrm{C} .{ }^{1} \mathrm{H}$ NMR (DMSO-d 6 , $500 \mathrm{MHz}$ ) 1.55 (br s, 4H), 1.84-1.96 (m, 2H), 2.02-2.12 (m, 2H), 2.16-2.22 (m, 2H), 2.35 (s, 3H), 2.68 $(\mathrm{s}, 3 \mathrm{H}), 2.73-2.78(\mathrm{~m}, 6 \mathrm{H}), 3.29-3.32(\mathrm{~m}, 4 \mathrm{H}), 3.87(\mathrm{~s}, 3 \mathrm{H}), 4.23-$ $4.32(\mathrm{~m}, 1 \mathrm{H}), 4.48(\mathrm{~d}, 2 \mathrm{H}, J=5.5 \mathrm{~Hz}), 6.19(\mathrm{~s}, 1 \mathrm{H}), 6.24(\mathrm{br} \mathrm{s}, 1 \mathrm{H})$, 6.66 (d, 2H, J = 8.6 Hz), 6.80 (br s, 1H), 6.88-6.93 (m, 2H), 6.99 (br s, 1H), 7.13 (br s, 1H), 7.64 (dd, 2H, J=8.6, $2.8 \mathrm{~Hz}$ ), 7.96-8.04 (m, 2H), 8.09-8.16 (m, 1H), $8.64(\mathrm{~s}, 1 \mathrm{H}), 11.81$ (br s, $1 \mathrm{H}) .{ }^{13} \mathrm{C}$ NMR (DMSO-d $\left.{ }_{6}, 125 \mathrm{MHz}\right)$ 11.8, 15.3, 23.4, 25.0, 26.6, 32.0, 35.4, $37.2(\times 2), 37.3,37.9,38.0,41.6,45.9,52.3,58.4,96.3,110.2$, 111.2 (2C), 113.1, 121.4, 122.4, 122.9, 126.3, 127.9, 128.2, 128.9 (2C) $140.8,142.1,148.5,150.7,153.8,156.3,159.3,161.1,166.0$, 166.2, 166.3, 167.3, 171.8, 172.3, 173.9, 196.5. HRMS (TOF) (m/ $z):[\mathrm{M}-\mathrm{Na}]^{-}$calcd for $\mathrm{C}_{45} \mathrm{H}_{51} \mathrm{NaN}_{12} \mathrm{O}_{8} \mathrm{~S}_{2}, 951.3400$; found, 951.3369 .

\section{Conflicts of interest}

There is no conflict to declare.

\section{Acknowledgements}

During this work, E. M. was supported by a trainee award from The Beatrice Hunter Cancer Research Institute (BHCRI) with funds provided by Cancer Care Nova Scotia as part of The Terry Fox Foundation Strategic Health Research Training Program in Cancer Research at Canadian Institutes of Health Research (CIHR). This work was funded by research grants to A. T. from: CIHR (Grant \# 133110), Canadian Breast Cancer FoundationAtlantic, Breast Cancer Society of Canada/QEII Foundation Awards for Breast Cancer Research, BHCRI and Nova Scotia Health Research Foundation. A. T. is a Senior Scientist of the BHCRI.

\section{References}

1 A. Fürstner, Angew. Chem., Int. Ed., 2003, 42, 3582-3603.

2 N. R. Williamson, P. C. Fineran, F. J. Leeper and G. P. Salmond, Nat. Rev. Microbiol., 2006, 4, 887-899.

3 R. K. Suryawanshi, C. D. Patil, H. P. Borase, C. P. Narkhede, A. Stevenson, J. E. Hallsworth and S. V. Patil, Int. J. Cosmet. Sci., 2015, 37, 98-107.

4 Y. Kim and J. Choi, Fibers Polym., 2015, 16, 1981-1987.
5 Y. Ren, J. Gong, R. Fu, Z. Li, Q. Li, J. Zhang, Z. Yu and X. Cheng, Dyes Pigm., 2017, 138, 147-153.

6 A. Fürstner and E. J. Grabowski, ChemBioChem, 2001, 2, 706709.

7 A. Fürstner, K. Reinecke, H. Prinz and H. Waldmann, ChemBioChem, 2004, 5, 1575-1579.

8 M. S. Melvin, J. T. Tomlinson, G. Park, C. S. Day, G. R. Saluta, G. L. Kucera and R. A. Manderville, Chem. Res. Toxicol., 2002, 15, 734-741.

9 M. S. Melvin, J. T. Tomlinson, G. R. Saluta, G. L. Kucera, N. Lindquist and R. A. Manderville, J. Am. Chem. Soc., 2000, 122, 6333-6334.

10 B. Montaner, W. Castillo-Avila, M. Martinell, R. Oellinger, J. Aymami, E. Giralt and R. Perez-Tomas, Toxicol. Sci., 2005, 85, 870-879.

11 S. Ohkuma, T. Sato, M. Okamoto, H. Matsuya, K. Arai, T. Kataoka, K. Nagai and H. H. Wasserman, Biochem. J., 1998, 334, 731-741.

12 G. Park, J. T. Tomlinson, M. S. Melvin, M. W. Wright, C. S. Day and R. A. Manderville, Org. Lett., 2003, 5, 113-116.

13 R. I. Sáez Díaz, S. M. Bennett and A. Thompson, ChemMedChem, 2009, 4, 742-745.

14 T. Sato, H. Konno, Y. Tanaka, T. Kataoka, K. Nagai, H. H. Wasserman and S. Ohkuma, J. Biol. Chem., 1998, 273, 21455-21462.

15 J. L. Seganish and J. T. Davis, Chem. Commun., 2005, 57815783.

16 W. R. Hearn, M. K. Elson, R. H. Williams and J. MedinaCastro, J. Org. Chem., 1970, 35, 142-146.

17 E. Marchal, S. Rastogi, A. Thompson and J. T. Davis, Org. Biomol. Chem., 2014, 12, 7515-7522.

18 E. Marchal, D. A. Smithen, I. M. Uddin, A. W. Robertson, D. L. Jakeman, V. Mollard, C. D. Goodman, K. S. MacDougall, S. A. McFarland, G. I. McFadden and A. Thompson, Org. Biomol. Chem., 2014, 12, 4132-4142.

19 E. Marchal, M. I. Uddin, D. A. Smithen, L. A. Hawco, M. Lanteigne, D. P. Overy, R. G. Kerr and A. Thompson, RSC Adv., 2013, 3, 22967-22971.

20 S. Rastogi, E. Marchal, I. Uddin, B. Groves, J. Colpitts, S. A. McFarland, J. T. Davis and A. Thompson, Org. Biomol. Chem., 2013, 11, 3834-3845.

21 J. Regourd, A. Al-Sheikh Ali and A. Thompson, J. Med. Chem., 2007, 50, 1528-1536.

22 R. I. Sáez Díaz, J. Regourd, P. V. Santacroce, J. T. Davis, D. L. Jakeman and A. Thompson, Chem. Commun., 2007, 2701-2703.

23 D. A. Smithen, A. M. Forrester, D. P. Corkery, G. Dellaire, J. Colpitts, S. A. McFarland, J. N. Berman and A. Thompson, Org. Biomol. Chem., 2013, 11, 62-68.

24 M. I. Uddin, S. Thirumalairajan, S. M. Crawford, T. S. Cameron and A. Thompson, Synlett, 2010, 2561-2564.

25 C. Ferrario and G. Batist, Expert Opin. Drug Discovery, 2014, 9, 647-668.

26 A. Cheung, H. J. Bax, D. H. Josephs, K. M. Ilieva, G. Pellizzari, J. Opzoomer, J. Bloomfield, M. Fittall, A. Grigoriadis, M. Figini, S. Canevari, J. F. Spicer, A. N. Tutt and S. N. Karagiannis, Oncotarget, 2016, 7, 52553-52574. 
27 R. Paulmurugan, R. Bhethanabotla, K. Mishra, R. Devulapally, K. Foygel, T. Sekar, J. Ananta, T. Massoud and A. Joy, Mol. Cancer Ther., 2016, 15, 221-231.

28 Y. Lu and P. S. Low, Adv. Drug Delivery Rev., 2002, 54, 675693.

29 J. Sudimack and R. J. Lee, Adv. Drug Delivery Rev., 2000, 41, 147-162.

30 F. Zagouri, M. A. Dimopoulos, E. Bournakis and C. A. Papadimitriou, Eur. J. Gynaecol. Oncol., 2010, 31, 268277.

31 Y.-S. Yi, Immune Netw., 2016, 16, 337-343.

32 W. Xia, A. R. Hilgenbrink, E. L. Matteson, M. B. Lockwood, J. X. Cheng and P. S. Low, Blood, 2009, 113, 438-446.

33 L. H. Matherly, Z. Hou and Y. Deng, Cancer Metastasis Rev., 2007, 26, 111-128.

34 J. M. Scott and D. G. Weir, J. Cardiovasc. Risk, 1998, 5, 223227.

35 R. Zhao, S. H. Min, Y. Wang, E. Campanella, P. S. Low and I. D. Goldman, J. Biol. Chem., 2009, 284, 4267-4274.

36 P. S. Low and S. A. SuKularatne, Curr. Opin. Chem. Biol., 2009, 13, 256-262.

37 S. Wang and P. S. Low, J. Controlled Release, 1998, 53, 39-48.

38 C. L. A. Hawco, E. Marchal, M. I. Uddin, A. E. G. Baker, D. P. Corkery, G. Dellaire and A. Thompson, Bioorg. Med. Chem., 2013, 21, 5995-6002.

39 G. Huang, D. Pemp, P. Stadtmüller, M. Nimczick, J. Heilmann and M. Decker, Bioorg. Med. Chem. Lett., 2014, 24, 4209-4214.

40 S. Dhar, Z. Liu, J. Thomale, H. Dai and S. J. Lippard, J. Am. Chem. Soc., 2008, 130, 11467-11476.

41 S. Zalipsky, Adv. Drug Delivery Rev., 1995, 16, 157-182.

42 M. P. Grillo, Expert Opin. Drug Metab. Toxicol., 2015, 11, 1281-1302.

43 H. Joyce, A. McCann, M. Clynes and A. Larkin, Expert Opin. Drug Metab. Toxicol., 2015, 11, 795-809.

44 A. Sullivan, A. Gibson, B. K. Park and D. J. Naisbitt, Expert Opin. Drug Metab. Toxicol., 2015, 11, 357-368.

45 R. S. Shirazi, K. K. Ewert, C. Leal, R. N. Majzoub, N. F. Bouxsein and C. R. Safinya, Biochim. Biophys. Acta, Biomembr., 2011, 1808, 2156-2166.

46 I. R. Vlahov and C. P. Leamon, Bioconjugate Chem., 2012, 23, 1357-1369.

47 C. Chen, J. Ke, X. E. Zhou, W. Yi, J. S. Brunzelle, J. Li, E.-L. Yong, H. E. Xu and K. Melcher, Nature, 2013, 500, 486-489.

48 M. P. Carrasco, E. A. Enyedy, N. I. Krupenko, S. A. Krupenko, E. Nuti, T. Tuccinardi, S. Santamaria, A. Rossello, A. Martinelli and M. A. Santos, Med. Chem., 2011, 7, 265-274. 49 S. K. Choi, T. Thomas, M.-H. Li, A. Kotlyar, A. Desai and J. R. Baker Jr, Chem. Commun., 2010, 46, 2632-2634.
50 A. Galbiati, C. Tabolacci, B. M. D. Rocca, P. Mattioli, S. Beninati, G. Paradossi and A. Desideri, Bioconjugate Chem., 2011, 22, 1066-1072.

51 L. Jiang, Z.-M. Gao, L. Ye, A.-Y. Zhang and Z.-G. Feng, Polymer, 2013, 54, 5188-5198.

52 H. Jing, Z. Guo, W. Guo, W. Yang, P. Xu and X. Zhang, Bioorg. Med. Chem. Lett., 2012, 22, 3418-3424.

53 C. Lainé, E. Mornet, L. Lemiègre, T. Montier, S. CammasMarion, C. Neveu, N. Carmoy, P. Lehn and T. Benvegnu, Chemistry, 2008, 14, 8330-8340.

54 P. Li, Y. Wang, F. Zeng, L. Chen, Z. Peng and L. X. Kong, Carbohydr. Res., 2011, 346, 801-806.

55 M. A. Santos, E. A. Enyedy, E. Nuti, A. Rossello, N. I. Krupenko and S. A. Krupenko, Bioorg. Med. Chem., 2007, 15, 1266-1274.

56 R. K. Singh, D. Rai, D. Yadav, A. Bhargava, J. Balzarini and E. De Clercq, Eur. J. Med. Chem., 2010, 45, 1078-1086.

57 A. F. Trindade, R. F. M. Frade, E. M. S. Macoas, C. Graca, C. A. B. Rodrigues, J. M. G. Martinho and C. A. M. Afonso, Org. Biomol. Chem., 2014, 12, 3181-3190.

58 P. M. Valencia, M. H. Hanewich-Hollatz, W. Gao, F. Karim, R. Langer, R. Karnik and O. C. Farokhzad, Biomaterials, 2011, 32, 6226-6233.

59 Y. Yang, Y. M. Zhang, Y. Chen, D. Zhao, J. T. Chen and Y. Liu, Chemistry, 2012, 18, 4208-4215.

60 H. Zhang, Z. Cai, Y. Sun, F. Yu, Y. Chen and B. Sun, J. Biomed. Mater. Res., Part A, 2012, 100, 2441-2449.

61 A. Bettio, M. Honer, C. Müller, M. Brühlmeier, U. Müller, R. Schibli, V. Groehn, A. P. Schubiger and S. M. Ametamey, J. Nucl. Med., 2006, 47, 1153-1160.

62 I. R. Vlahov, H. K. Santhapuram, P. J. Kleindl, S. J. Howard, K. Stanford and C. P. Leamon, Bioorg. Med. Chem. Lett., 2006, 16, 5093-5096.

63 W. A. Henne, S. A. Kularatne, J. Hakenjos, J. D. Carron and K. L. Henne, Bioorg. Med. Chem. Lett., 2013, 23, 5810-5813.

64 T. Suzuki, S. Hisakawa, Y. Itoh, N. Suzuki, K. Takahashi, M. Kawahata, K. Yamaguchi, H. Nakagawa and N. Miyata, Bioorg. Med. Chem. Lett., 2007, 17, 4208-4212.

65 M. Nomura, S. Shuto and A. Matsuda, J. Org. Chem., 2000, 65, 5016-5021.

66 C. P. Leamon, M. A. Parker, I. R. Vlahov, L. C. Xu, J. A. Reddy, M. Vetzel and N. Douglas, Bioconjugate Chem., 2002, 13, 1200-1210.

67 J. D. Seitz, J. G. Vineberg, E. Herlihy, B. Park, E. Melief and I. Ojima, Bioorg. Med. Chem., 2015, 23, 2187-2194.

68 E. Vlashi, L. E. Kelderhouse, J. E. Sturgis and P. S. Low, ACS Nano, 2013, 7, 8573-8582.

69 J. Luo, M. D. Smith, D. A. Lantrip, S. Wang and P. L. Fuchs, J. Am. Chem. Soc., 1997, 119, 10004-10013. 